OPEN ACCESS

Edited by:

John S. Gunn

The Research Institute at Nationwide Children's Hospital, United States

Reviewed by: Robert W. Crawford, California State University, Sacramento, United States Brian Joseph Balin, Philadelphia College of Osteopathic Medicine, United States

*Correspondence:

Robert O. Watson robert.watson@medicine.tamhsc.edu

Specialty section:

This article was submitted to Molecular Bacterial Pathogenesis, a section of the journal Frontiers in Cellular and Infection Microbiology

Received: 01 March 2019 Accepted: 16 April 2019 Published: 28 May 2019

Citation:

Patrick KL, Bell SL, Weindel CG and Watson RO (2019) Exploring the

"Multiple-Hit Hypothesis" of Neurodegenerative Disease: Bacterial Infection Comes Up to Bat. Front. Cell. Infect. Microbiol. 9:138. doi: 10.3389/fcimb.2019.00138

\section{Exploring the "Multiple-Hit Hypothesis" of Neurodegenerative Disease: Bacterial Infection Comes Up to Bat}

\author{
Kristin L. Patrick, Samantha L. Bell, Chi G. Weindel and Robert O. Watson* \\ Department of Microbial Pathogenesis and Immunology, Texas A\&M Health Science Center, Bryan, TX, United States
}

Despite major strides in personalized genomics, it remains poorly understood why neurodegenerative diseases occur in only a fraction of individuals with a genetic predisposition and conversely, why individuals with no genetic risk of a disorder develop one. Chronic diseases like Alzheimer's, Parkinson's, and Multiple sclerosis are speculated to result from a combination of genetic and environmental factors, a concept commonly referred to as the "multiple hit hypothesis." A number of bacterial infections have been linked to increased risk of neurodegeneration, and in some cases, clearance of bacterial pathogens has been correlated with amelioration of central nervous system (CNS) deficits. Additionally, mutations in several genes known to contribute to CNS disorders like Parkinson's Disease have repeatedly been implicated in susceptibility to intracellular bacterial infection. Recent data has begun to demonstrate roles for these genes (PARK2, PINK1, and LRRK2) in modulating innate immune outcomes, suggesting that immune dysregulation may play an even more important role in neurodegeneration than previously appreciated. This review will broadly explore the connections between bacterial infection, immune dysregulation, and CNS disorders. Understanding this interplay and how bacterial pathogenesis contributes to the "multiple-hit hypothesis" of neurodegeneration will be crucial to develop therapeutics to effectively treat both neurodegeneration and infection.

Keywords: pathogenesis, Parkinson's, Alzheimer's, neuroinflammation, Parkin (PARK2), LRRK2, PINK1, Mycobacterium tuberculosis

\section{INTRODUCTION}

Worldwide, an estimated 50 million people suffer from dementia/Alzheimer's Disease (AD), 710 million from Parkinson's Disease (PD), and over 2 million from Multiple sclerosis (MS). As our population ages, the incidence of neurodegenerative disease will continue to soar. The vast majority of neurodegenerative disease cases occur in people who have no known family history of the disorder. Current estimates state that only $15 \%$ of PD patients carry a mutation in a known Parkinson's-related factor (e.g., LRRK2, PARK2/Parkin, PINK1, or SNCA). While earlyonset familial $\mathrm{AD}$ has a strong genetic component [e.g., mutations in amyloid precursor protein $(A P P)$, presenilin-1 (PS1), and presenilin-2 (PS2)], researchers have not identified genetic causes of late-onset $\mathrm{AD}$, although the $A P O E$ e4 allele is associated with increased risk. Likewise, despite the identification of over 200 genes that may contribute to MS risk (e.g., HLA-DRB1, IL7R), the actual 
factors that precipitate demyelination of neurons and why these changes occur at a specific time in an individual's life remain unclear.

Clearly, factors beyond genetics are involved in precipitating and exacerbating diseases of the CNS. For decades, infections by viruses, bacteria, or eukaryotic parasites have been investigated as possible triggers for neurodegeneration. While many researchers remain skeptical of studies in human patients that suffer from small sample size and complicating co-morbidities, a preponderance of evidence strongly implicates an infectious component in neurodegenerative diseases. MS is perhaps the best described CNS disorder with a potential microbial trigger, as several latent viral infections, including herpes and Epstein-Barr, increase one's risk for MS. However, no infection has been identified as truly causal. A recent study that investigated "infection burden" in a cohort of PD patients and healthy controls measured antibody titers for a number of infections that have been associated with neurodegeneration including cytomegalovirus (CMV), Epstein Barr virus (EBV), herpes simplex virus (HSV-1), Borrelia burgdorferi, Chlamydia pneumoniae, and Helicobacter pylori (Bu et al., 2015). They reported that $\mathrm{PD}$ patients were statistically more likely to have been exposed to multiple pathogens relative to healthy controls. This likelihood was particularly robust when bacterial pathogens were assessed independently of viral infection. Along these same lines, other studies have found that vaccination against formerly common bacterial infections (diphtheria, tetanus, pertussis) associates with decreased risk for $\mathrm{AD}$ (Verreault et al., 2001).

One obvious consequence of infection is peripheral inflammation and polarization of immune responses. While interest in neuroinflammation and how resident brain immune cells, like microglia and astrocytes, make and respond to cytokines and chemokines is growing, how these variables impact cells in the brain remains vastly understudied. Dysregulation of the gut microbiome has received a great deal of attention as a risk factor for CNS dysfunction and has been reviewed extensively (Zhu et al., 2017; Bell et al., 2018; Heiss and Olofsson, 2019). Here, we will focus on pathogenic bacterial species that have repeatedly been associated with three major neurodegenerative diseases: AD, PD, and MS (Figure 1). We will broadly describe the current evidence that supports a role for peripheral immune responses in eliciting $\mathrm{AD}, \mathrm{PD}$, and $\mathrm{MS}$ and highlight how specific bacterial pathogens have been linked to neurodegenerative diseases. Finally, as the links between PD and mycobacterial infections have been investigated with some mechanistic detail, we will explore the evidence that supports the "multiple-hit hypothesis" for PD.

\section{Local and Peripheral Immune Responses in Neurodegenerative Diseases}

For decades, the CNS has been perceived as an immune privileged site, shut off from the peripheral immune response by virtue of the blood-brain barrier (BBB) and a lack of draining lymphatics. However, more recent data have repeatedly challenged this paradigm, showing that extensive mixing occurs between the CNS immune milieu and that of the periphery, with circulating proteins and metabolites able to access the brain. This shift in thinking allows us to seriously consider the idea that changes to the peripheral immune response can elicit neuroprotective and neurotoxic changes in the CNS.

\section{Parkinson's Disease}

$\mathrm{PD}$ is characterized by loss of dopaminergic neurons that originate in the substantia nigra (SNc) and deposit dopamine in the striatum. The striatum is a principle component of the basal ganglia, a group of neurons involved in coordinating voluntary movement. It serves as the reward and motor center of the brain. As these SNc-originating neurons deteriorate, dopamine levels in the striatum plummet, resulting in the motor deficits generally associated with PD (slow movement, tremors, rigidity). Because the striatum is also part of the brain's reward circuit, PD patients frequently suffer from depression and anxiety, likely due to decreased dopamine levels. The brains of PD patients accumulate protein deposits called Lewy bodies, which are mainly comprised of aggregates of the protein $\alpha$-synuclein. Accumulation of $\alpha$ synuclein deposits ultimately results in neuronal dysfunction. Levodopa, or L-3,4-dihydroxyphenylalanine, is a precursor to dopamine and the default treatment for PD-patients to improve parkinsonian symptoms in early disease stages. Levodopa is generally quite effective and well-tolerated but many patients experience response fluctuations as a consequence of irregular absorption and short drug half-life (Salat and Tolosa, 2013).

Approximately $95 \%$ of PD patients have idiopathic disease. The vast majority of these cases are likely caused by the combination of any number of extrinsic factors, including but not limited to infection, dysregulation of gut microbiota, and exposure to environmental toxins. Together, these stresses may directly damage healthy neurons, while also inducing expression of proinflammatory and cytotoxic factors by microglia and astrocytes. Over time, a positive feedback loop persists, whereby activation of these CNS resident immune cells damages neurons, thereby activating glial cells and inducing additional neuroinflammation.

Somewhat paradoxically, low levels of proinflammatory cytokines (IFN- $\beta$, IL- $1 \beta$, IL-6, TNF- $\alpha$ ) are absolutely required for the maintenance of a healthy brain and have been shown to aid in remodeling of neurocircuits and in neurogenesis (Yirmiya and Goshen, 2011). For example, Ifnb ${ }^{-/-}$mice exhibit spontaneous behavioral and cognitive impairments and neurodegeneration. PD-like symptoms and dopaminergic neuron loss were preventable with IFN- $\beta$ gene therapy (Ejlerskov et al., 2015). While this is indicative of a neuroprotective role for type I IFN, increased type I IFN expression has also been found in the brain tissue of post mortem PD patients, and type I IFN receptor (IFNAR) function is required in the 1-methyl-4-phenyl1,2,3,6-tetrahydropyridine (MPTP) induced mouse model of PD (Main et al., 2016). These data imply that the dysregulation of type I IFN has diverse effects in PD progression, similar to its complex role in many other inflammatory conditions.

PD elicits strong innate and adaptive immune responses that can be detected in the CNS as well as in circulating serum. Two of the earliest biomarkers for PD include TNF- $\alpha$ and IL-1 $\beta$. These 


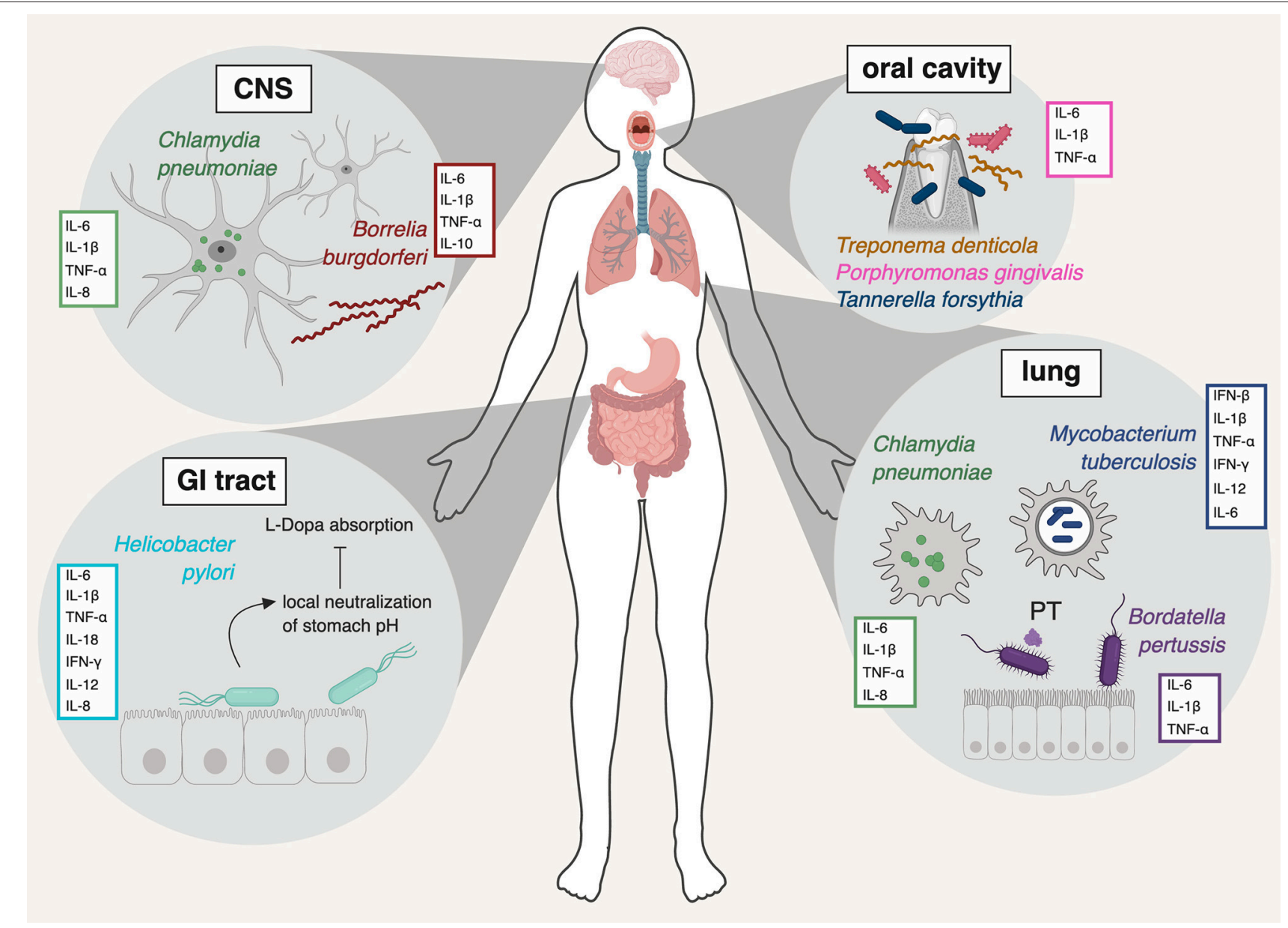

FIGURE 1 | Schematic representation of the pathogens discussed in this review, the major organ system(s) they infect, and the primary innate immune cytokines they induce. Chlamydia pneumoniae is shown in its primary location (lung) but also in the CNS, where the bacterium has been repeatedly detected in association with AD (Balin et al., 1998; Arking et al., 1999; Gérard et al., 2006). Borrelia burgdorferi is a systemic infection, shown here in the CNS, where it too has been detected (Miklossy et al., 2004). Helicobacter pylori causes infection of the stomach and duodenum. Mycobacterium tuberculosis and Bordatella pertussis are mainly pathogens of the lung. The major resident oral pathogens, Treponema denitcola, Porphyromonas gingivalis, and Tannerella forsythia are shown in the mouth and gums. PT: pertussis toxin. Figure created with BioRender.

cytokines, along with IL-2, IL-6, IL-8, CCL2, and IFN- $\gamma$, are elevated in the brains, cerebrospinal fluid (CSF), and blood of PD patients (Eidson et al., 2017; Schröder et al., 2018). A recent study showed that T cells from patients with PD recognize $\alpha$ synuclein (Sulzer et al., 2017), and non-classical monocytes and reactive $\mathrm{CD} 4+$ and $\mathrm{CD} 8+$ reactive $\mathrm{T}$ cells are found in postmortem brain tissue (Brochard et al., 2009; Sommer et al., 2018), indicating elevated inflammation as well as adaptive immune cell invasion into PD-patient brains. In the periphery, IFN$\gamma / \mathrm{IL}-4$ ratios are elevated in PD patients, demonstrating that the majority of reactive $\mathrm{T}$ cells are Th1 (Kustrimovic et al., 2018). Other reports have implicated pro-inflammatory Th17 cells in PD progression (Storelli et al., 2019). Together, these data strongly suggest an adaptive immune component to the pathophysiology of PD. PD may also have a humoral immune component, as increased IgG antibodies have been found against $\alpha$-synuclein and dopaminergic neurons in patients with advanced disease. This suggests that antibodies are capable of crossing the
BBB during active PD (Sanchez-Guajardo et al., 2013), but the contribution of IgG antibodies to earlier disease stages remains unclear (Scott et al., 2018). Because innate immune responses are critical in determining adaptive immune cell engagement and differentiation, it is possible that many of the $\mathrm{T}$ and $\mathrm{B}$ cell phenotypes described here occur downstream of innate immune responses following general stresses like mitochondrial damage or infection.

\section{Alzheimer's Disease}

$\mathrm{AD}$ is a disease of cognitive impairment rather than motor function deterioration. $\mathrm{AD}$ is characterized by synaptic loss in the cortex and hippocampus, alongside the presence of plaques and neurofibrillary tangles. These plaques are mainly comprised of amyloid beta peptide, which is derived by proteolytic cleavage of amyloid beta precursor protein (A $\beta$ PP or APP). Gradual accumulation of these plaques correlates with synaptic loss and neuronal death. Likewise, neurofibrillary tangles are 
comprised of tau, a protein that associates with microtubules in mature neurons and helps stabilize the microtubule network. Hyperphosphorylated tau, which is seen in the brains of $\mathrm{AD}$ patients, is prone to oligomerize, which inhibits trafficking along microtubules and promotes formation of nonfunctional and toxic neurofibrillary tangles (Iqbal et al., 2010).

Like PD, infection and inflammation have been repeatedly associated with $\mathrm{AD}$ although the exact nature of these environmental factors remains unclear. Several lines of compelling evidence support a "multiple-hit hypothesis" for triggering $\mathrm{AD}$. Notably, several $\mathrm{AD}$ risk-associated genes including APP, APOE, and TREM2, have been associated with immune activation, and a number of bacterial pathogens (e.g., H. pylori, C. pneumoniae, and Porphyromonas gingivalis) have been detected in the brains of AD patients (Price et al., 2006; Harris and Harris, 2015; Miklossy, 2015; Pisa et al., 2015; Carter, 2017). In addition, proinflammatory cytokines and immune cells have been implicated in AD disease progression. IL- $1 \beta$ has been shown to regulate the processing of APP, altering its levels ( $\mathrm{Li}$ et al., 2003; Griffin et al., 2006; Tachida et al., 2008; Anderson et al., 2009). Similarly, IL-6, IL-18, IL-10, TNF- $\alpha$, and TGF- $\beta 1$ seem to play a role in APP metabolism and tau phosphorylation (Domingues et al., 2017). IFN- $\gamma$ has been shown to promote phagocytosis of APP, thus promoting plaque clearance, but IFN- $\gamma$ also induces production of IL-18 and IL- $1 \beta$, which are associated with increased disease severity (Kim et al., 2000; Joosten et al., 2003). Treatment with TGF- $\beta 1$ (Chen et al., 2015) or IFN- $\beta$ (Mudò et al., 2019) are protective in rat models of $\mathrm{AD}$ and are thought to work by decreasing proinflammatory IL- $1 \beta$, TNF- $\alpha$, and iNOS, and by promoting anti-inflammatory IL-10. Both $\mathrm{AD}$ patients and $\mathrm{AD}$ animal models present high $\mathrm{CD} 4+/ \mathrm{CD} 8+\mathrm{T}$ cell ratios indicative of Th1 skewing in the periphery (Browne et al., 2013), and elevated levels of IL-6, IL-21, IL-22, IL-23 in the serum of AD patients point to a Th17 polarization in the periphery during early disease (Oberstein et al., 2018). Together, these data strongly implicate an immune component in triggering, exacerbating, and protecting against $\mathrm{AD}$, and demand further investigation into how infection influences each of these phenomena.

\section{Multiple Sclerosis}

MS differs from $\mathrm{PD}$ and $\mathrm{AD}$ in that is an autoimmune disease whereby $\mathrm{T}$ cells attack the myelin sheath of neurons, preferentially in the optic nerve, brainstem, spinal cord, and subcortical areas of the brain. Activation of CNS-sensitized T cells damages not only myelin but also myelin-producing cells called oligodendrocytes and nerve fibers. Deterioration of myelin sets off an inflammatory process that triggers the recruitment of immune cells into the CNS and the release of inflammatory cytokines. Symptoms are varied but include muscle weakness, ataxia, visual problems, and acute or chronic pain. Symptomatic episodes can occur without warning, but common infections like influenza and gastroenteritis increase risk of relapse (Compston and Coles, 2008).

Interestingly, patients with MS have elevated circulating cytokines involved in chemotaxis including, CCL2, CCL3, CCL4, CXCL10, MIF, and Trail as well as IL-17 and IL-12(p40); many of these immune modulators have also been detected in patients' CSF (Khaibullin et al., 2017). These chemokines likely promote the infiltration of reactive $\mathrm{T}$ cells (IL-17-producing Th17 cells and GM-CSF-producing CD4+ and CD8 $+\mathrm{T}$ cells) into the brain, contributing to the death of neurons (Cao et al., 2015; Pierson and Goverman, 2017). Monocyte infiltration into the CNS also occurs, facilitated by IL-1 $\beta$ (Paré et al., 2018). The exact mechanism by which $\mathrm{T}$ cell populations or monocytes initially gain access to the brain is not well understood, but evidence points to roles IL-17 and IL-22 via breakdown of the $\mathrm{BBB}$ and modulation of resident immune cells of the brain (Kebir et al., 2007).

Type I and Type II IFNs seem to play paradoxical roles in MS, either promoting protection or pathogenesis depending on the stage of the disease (Arellano et al., 2015). In early stages of rodent MS, IFN- $\gamma$ (type II IFN) produced by natural killer (NK) cells promotes a pro-inflammatory state by increasing M1 macrophages and promoting $\mathrm{T}$ cell infiltration into the brain, thus exacerbating disease (Dungan et al., 2014). In later stages of disease, however, IFN- $\gamma$ actually attenuates inflammation (Furlan et al., 2001). Likewise, IFN- $\beta$ (type I IFN) has been shown to decrease GM-CSF by CD4+ and CD8+ T cells, thereby limiting $\mathrm{T}$ cell infiltration into the brain, but it can also exacerbate disease in the absence of IFN- $\gamma$ (Rasouli et al., 2015).

\section{BACTERIAL PATHOGENS ASSOCIATED WITH NEURODEGENERATION}

\section{Helicobacter pylori}

H. pylori is a ubiquitous gram-negative, motile bacterium found in the stomach/upper gastrointestinal tract of approximately $50 \%$ of humans. Although the majority of infected individuals do not experience symptoms, $H$. pylori can cause gastritis and peptic ulcers and is associated with stomach cancer. Several adaptations are required for $H$. pylori to survive in and colonize the GI tract including secretion of urease, flagellar motility, and adhesion to the gastric epithelium.

H. pylori infection induces a pro-inflammatory innate immune response. One important way $H$. pylori induces inflammation is via the activity of genes in its cag pathogenicity island, which has been shown to mediate epithelial cell contact and promote IL-8 expression. Because its lipopolysaccharide (LPS) is a relatively weak inducer of toll-like receptor 4 (TLR4), most NFKB-dependent cytokine expression (e.g., IL-6, TNF $\alpha$ ) is activated via TLR2 from its outermemberane lipoproteins. By virtue of it being a mucosal pathogen, mast cells and eosinophils are important cellular players in $H$. pylori gastritis (Ieni et al., 2016). Th1 cells are also critical as they dominate the T-cell response in the gastric mucosa and result in increased severity of gastritis (Robinson et al., 2007). This Th1-mediated response results in high levels of IFN- $\gamma$, TNF- $\alpha$, and IL-12. H. pylori infection also promotes expression of IL-1 family cytokines, IL$1 \beta$ and IL-18, due to inflammasome activation. Importantly, many of $H$. pylori-induced cytokines have been independently linked to exacerbation of PD (TNF- $\alpha$, IFN- $\gamma$, IL-1 $\beta$ ) and AD (IL-1 $\beta$ and IL-18) (Semper et al., 2014). 
Various studies have found that a large percentage of PD patients test positive for active $H$. pylori [70\% H. pylori-positive (Dobbs et al., 2012), 53\% positive (Lee et al., 2008), 32.4\% positive (Tan et al., 2015)]. A study of patients in Denmark reported that patients who had been treated for $H$. pylori infection were at increased risk for developing PD (45\% for H. pylori-eradication drugs and $23 \%$ for proton-pump inhibitors) (Nielsen et al., 2012), suggesting chronic H. pylori infection and/or gastritis precede PD symptoms. However, because H. pylori is a common pathogen with global distribution, these associations are not particularly surprising.

Because $H$. pylori survival and replication requires local neutralization of the acidic gastrointestinal tract, infection is frequently associated with drug malabsorption, and $H$. pylori infection seems to diminish response to levodopa (L-dopa) therapy. H. pylori-infected patients showed a delay in L-dopa onset (the time it take for the drug to "kick in") versus uninfected patients (Pierantozzi et al., 2001; McGee et al., 2018). Consequently, antibiotic treatment of $H$. pylori led to marked improvement of symptoms in $\mathrm{PD}$ patients receiving L-dopa therapy (Hashim et al., 2014). H. pylori clearance may improve therapeutic efficacy due to the bacterium's ability to neutralize the $\mathrm{pH}$ of the stomach. H. pylori secretes urease to break urea down into carbon dioxide and ammonium in order to neutralize stomach acid and create a region of neutral $\mathrm{pH}$ around the bacterium. These H. pylori-dependent fluctuations in stomach $\mathrm{pH}$ are thought to influence the absorption of L-dopa in the duodenum, and there is strong clinical evidence to support this mechanism. For example, higher L-dopa blood serum levels can be measured in $H$. pylori-positive patients treated with antibiotics compared to $H$. pylori-positive patients receiving antioxidant therapy (Pierantozzi et al., 2006). Additionally, PD patients receiving L-dopa following treatment with $H$. pylorispecific antimicrobials have improved hypokinesia (Dobbs et al., 2013). However, to date no study looking at $H$. pylori clearance following antibiotic treatment has assessed the status of patients' gut microflora pre- and post-treatment. Therefore, it is difficult to say definitively whether it is solely the eradication of $H$. pylori that impacts PD symptoms and L-dopa efficacy in antibiotictreated patients since interplay through the gut-brain-axis is also correlated with PD (Zhu et al., 2017). Indeed, H. pyloridependent alteration of the microbiome and the gut-brain-axis may influence PD outcomes in a number of ways, including altering permeability of the BBB to inflammatory mediators or immune cells (Braniste et al., 2014).

H. pylori has also been associated with AD. Kountouras et al. report that $\mathrm{AD}$ patients had significantly higher levels of anti- $H$. pylori IgG antibodies in their CSF and serum. While higher levels of anti- $H$. pylori IgG antibodies in the CSF could be an indirect result of changes to the permeability of the $\mathrm{BBB}$, these antibodies also correlated with lower mini-mental state examination scores compared to those of healthy controls (Kountouras et al., 2009). These conclusions remain controversial, however, as recent investigations found no increased risk of $\mathrm{AD}$ in $H$. pyloriinfected patients (Fani et al., 2018) or only found increased risk in certain population groups, specifically in men and in higher socioeconomic status groups, both of which have higher incidence of complicating co-morbidities like cardiovascular disease (Beydoun et al., 2018).

Interestingly, meta-analyses have demonstrated an opposite trend between $H$. pylori and MS; several studies have found a significantly lower prevalence of $H$. pylori infection in patients with MS (Li et al., 2007; Jaruvongvanich et al., 2016; Yao et al., 2016). The inverse correlation between $H$. pylori and MS is particularly significant in Western countries (Yao et al., 2016). Consistent with these patient studies, pre-infection of C57BL/6 mice with $H$. pylori prior to induction of a mouse model of MS (EAE, experimental autoimmune encephalomyelitis) resulted in significantly reduced clinical scores and fewer CD4+, CD8+, Th1, and Th17 cells in the CNS (Cook et al., 2015). Together, these data suggest that some inflammation-inducing pathogens may elicit immune responses that are actually protective for certain CNS diseases, such as in MS where there is an autoimmune component. Although the mechanisms and cell types that drive these divergent outcomes remain unclear, many independent lines of evidence that support a role for $H$. pylori infection in influencing CNS dysfunction.

\section{Bordetella pertussis}

Bordatella pertussis is a gram-negative bacterium that causes an infection of the lungs that presents as pertussis, or whooping cough. B. pertussis uses a protein called filamentous haemagglutinin to bind to ciliated epithelial cells and colonize the respiratory tract. Its primary mechanism of pathogenesis utilizes a secreted toxin (pertussis toxin, PT) that becomes active after the bacterium is endocytosed into host cells. Once active, PT blocks G-protein signaling, leading to increased cellular concentrations of cAMP and inhibition of cellular signal transduction, impacting the ability of cells to respond to a number of extracellular signals, including hormones, chemokines, and cytokines (Lattin et al., 2007).

While vaccination is incredibly effective in preventing $B$. pertussis infection and spread, incidences of pertussis are high in regions where vaccination coverage is low; a recent modeling study purports there may be as many as 24 million cases of pertussis per year worldwide (Yeung et al., 2017). While vaccination prevents acute clinical pertussis risk, it does not prevent subclinical infection (Ward et al., 2005; Warfel et al., 2014; Zhang et al., 2014), and it is hypothesized that chronic, asymptomatic B. pertussis colonization may influence CNS dysfunction. Although there is no evidence for the bacterium itself entering the CNS, researchers have speculated that PT can reach the CNS following absorption from the nasal mucosa. Again, while direct evidence for this popular hypothesis is still lacking, experiments have shown that PT can decrease BBB integrity and promote transmigration of monocytes in a human brain-derived microvascular endothelial cell model of the BBB (Kügler et al., 2007). If these results translate to an in vivo infection, this action of PT has the potential to expose the CNS to the toxin, pathogen, or other components of the host immune response.

The immune response to $B$. pertussis infection has a Th1/proinflammatory cytokine signature characteristic of innate immune sensing through TLR-4 (i.e., IL-1 $\beta$, TNF- $\alpha$, IL-6). When Loscher 
et al. challenged mice via aerosolized $B$. pertussis, they detected pro-inflammatory cytokines by ELISA in the lungs, circulating plasma, hypothalamus, and hippocampus (Loscher et al., 2000a). The same group detected IL- $1 \beta$, TNF- $\alpha$, and IL- 6 mRNA in the hypothalamus at various time points following $B$. pertussis infection, suggesting that peripheral infection with this pathogen is sufficient to trigger gene expression in regions of the brain (Loscher et al., 2000b). While the authors argue they can detect cytokine mRNA in infected brains well after bacterial loads in the lungs have cleared (day 42 post-infection), the authors do not formally control for bacteria accessing the brain or other organs.

Chronic asymptomatic infection with $B$. pertusiss has been linked to the development of $\mathrm{AD}$. Experiments in mice have shown that pertussis infection triggers production of $A \beta_{40}$, a proteolytic product of amyloid precursor protein that is an important biomarker for AD (McManus et al., 2014). Specifically, aged AD-model mice [overexpressing APP and harboring mutations in presinilin 1 (PS1)] had significantly higher levels of insoluble $A \beta_{40}$ when infected with $B$. pertussis (McManus et al., 2014). B. pertussis-infected animals also had more $A \beta_{40}$ plaques, increased $\mathrm{T}$ cell infiltration into the brain, elevated macrophage/microglial activation, and increased inflammatory cytokines in brain cortical tissue. Likewise, pertussis toxin itself has been shown to dramatically reduce $A \beta_{40}$ clearance in a mouse microglia cell line (BV-2) (Tahara et al., 2006). Because of the multifactorial nature of $B$. pertussis infection, it is unclear whether PT, the pathogen itself, the immune response, or a combination of these factors, contributes to changes in the CNS.

\section{Chlamydia pneumoniae}

Chlamydia pneumoniae is a gram-negative obligate intracellular bacterium and a common cause of upper respiratory infections, including acute pneumonia and bronchitis. Chlamydial elementary bodies, which are metabolically inactive but infective, attach to and are phagocytosed by macrophages. C. pneumoniae can also infect respiratory epithelial cells in the lungs (Jahn et al., 2000). Once inside a host cell, elementary bodies mature into reticulate bodies, replicate, and differentiate back into elementary bodies, which are released to begin the cycle again. While lysis of host cells is crucial for C. pneumoniae spread during acute infection, the bacterium can inhibit apoptosis during chronic infection, allowing for persistence (Rajalingam et al., 2001). As C. pneumoniae can infect a variety of cell types, it induces expression of an array of cytokines and chemokines, notably the inflammatory mediators IL-6, IL- $1 \beta$, IL- 8 , and TNF- $\alpha$, and cell adhesion molecules ICAM-1 and VCAM-1 (Kern et al., 2009; Lim et al., 2014).

Despite being primarily categorized as an infection of the lungs, C. pneumoniae is also widely associated with cardiovascular disease and atherosclerotic plaque formation. $C$. pneumoniae can damage blood vessels either directly by infecting endothelial cells and vascular smooth muscle cells or indirectly by infecting monocytes/macrophages that damage tissues via inflammation and oxidative bursts (Di Pietro et al., 2017). C. pneumoniae is also associated with cerebrovascular disease and cerebral infarction (stroke). A recent meta-analysis suggested that cerebral infarction patients were significantly more likely to be seropositive for C. pneumoniae infection compared to healthy controls (Su and Chen, 2014).

Because of its well-established role in pathology outside of the lungs and in plaque formation, it is perhaps unsurprising that connections between C. pneumoniae and CNS pathology are beginning to emerge. Several groups have detected $C$. pneumoniae in patient brains by PCR (Arking et al., 1999; Sriram et al., 2005; Gérard et al., 2006). However, the route that $C$. pneumoniae uses to reach the brain remains unclear. Because $C$. pneumoniae is a respiratory infection, both olfactory and lung infection routes are possible. Recent comparative genomics experiments studying strains isolated from or previously identified in the human heart, brain, and lung found that the brain-associated strain (TOR-1) was more similar to the respiratory strain (AR39) than to cardiac-associated strains, suggesting a lung-to-brain migration (Roulis et al., 2015). Such migration could be mediated by infected monocytes capable of crossing the BBB. Ex vivo studies using human brain microvascular endothelial cells (HBMECs) to mimic the BBB, showed that THP-1 monocytic cells infected with $C$. pneumoniae had an enhanced ability to transmigrate through the endothelial monolayer (MacIntyre et al., 2003). Consistent with this, MacIntyre et al. observed an upregulation of adhesion molecules like LFA-1, VLA-4, and MAC-1 in infected monocytes, suggesting that $C$. pneumoniae infection can alter cell-intrinsic qualities of macrophages to enhance their ability to cross the BBB and promote migration into the CNS.

While the mechanism and implications of C. pneumoniae brain infiltration remains unclear, associations between $C$. pneumoniae and CNS disorders are quite strong. In one study, C. pneumoniae DNA was amplified from $90 \%$ of postmortem brains of patients diagnosed with late-onset dementia of the Alzheimer's type, compared to just 5\% of healthy control brains (Balin et al., 1998). Another more recent PCR-based study showed that 20/25 AD patients but only 3/27 control patients were PCR-positive for C. pneumoniae (Gérard et al., 2006). Using immunohistochemistry, the same study observed that CNS cells harboring C. pneumoniae were often found in close proximity to both neurofibrillary tangles and neuritic senile plaques, which are comprised of $A \beta_{40}$ and associated with late-onset $A D$ (Gérard et al., 2006).

C. pneumoniae has also been connected to MS. In one landmark study, C. pneumoniae DNA was found in the CSF of $36 / 37 \mathrm{MS}$ patients vs. 5/27 control patients with other neurological disorders. These same MS patients were also more likely to have anti-C. pneumoniae IgG (32/37 in MS vs. $0 / 27$ in controls) (Sriram et al., 1999). However, since this initial publication, a number of groups have been unable to culture C. pneumoniae from the CSF or brain tissue of MS patients, and additional PCR detection approaches have also been unsuccessful (Gieffers et al., 2000; Ring and Lyons, 2000). Some of these technical difficulties may result from the complicated intracellular lifestyle of C. pneumoniae; because it is an obligate intracellular pathogen it cannot freely replicate in a niche like the CSF and is difficult to culture ex vivo. Because of these caveats, the presence of C. pneumoniae in the CNS of MS patients 
and the implications of these findings for MS pathogenesis remain divisive.

\section{Periodontal Bacteria}

Periodontitis is a common chronic inflammatory disease caused by a number of oral resident bacteria that leads to inflammation of the gums and damage to teeth themselves. The main bacterial species associated with periodontitis are $P$. gingivalis, Tannerella forsythia, and Treponema denticola. All are gram-negative, obligate anaerobes specialized to live in the diverse microbial community of the oral cavity. The immune response associated with periodontitis involves both innate and adaptive immune cells, with inflammatory mediators like IL$1 \beta$, TNF- $\alpha$, IL- 6 , contributing not only to tissue damage of the gums but also osteoclastogenesis (breakdown of bone tissue) (Cekici et al., 2014).

In recent years, there has been an explosion of studies investigating connections between oral bacteria and neurodegenerative diseases like $\mathrm{AD}$. A retrospective cohort study of patients in Taiwan found that patients with chronic periodontal disease ( $>10$ year exposure) had a 1.707-fold increased risk of developing $\mathrm{AD}$ (Chen et al., 2017). GWAS database studies looking at genes in the $P$. gingivalis/host interactome identified significant overlap between host factors and genes involved in cognitive disorders, $\mathrm{AD}$, and dementia. Similar studies also found that the gene expression profiles of macrophages exposed to live $P$. gingivalis, its LPS, or its fimbrae closely matched the expression profiles of hippocampuses from post-mortem AD patients (Carter et al., 2017). Together, these results suggest that periodontal bacteria, and especially $P$. gingivalis, may elicit inflammatory gene expression programs similar to those associated with neurodegeneration.

Evidence for periodontal bacteria in the brain itself remains controversial. To date, most studies of the relationship between periodontal infections and systemic disease have used the ApoE $E^{-/-}$mouse model. APOE mediates lipoprotein uptake by the LDL receptor and plays an important role in atherosclerosis and $\mathrm{AD}$. When $A p o E^{-/-}$mice were chronically infected with $P$. gingivalis via oral lavage (repeated inoculations over a course of 12 or 24 weeks), Poole et al. detected bacterial genomic DNA in the brains of $50 \%$ of the $A p o E^{-/-}$mice, compared to $0 \%$ of the matched controls. The authors speculate that migration of $P$. gingivalis into the brain implicate ApoE in maintaining the integrity of the BBB (Poole et al., 2015). Indeed, $A p o E^{-/-}$ mice have been shown to experience increased cortical $\mathrm{BBB}$ leakage as they age compared to wild-type controls (HafeziMoghadam et al., 2007). Other studies of $P$. gingivalis-infected $A p o E^{-/-}$mice found higher incidence of $P$. gingivalis bacteria in the frontotemporal lobe by fluorescence in situ hybridization, which correlated with an increase in age-related granules (astrocyte-associated inclusions observed in the hippocampus of senescence-accelerated mouse models) (Singhrao et al., 2017). In humans, LPS from $P$. gingivalis has been detected in postmortem AD brain tissue (Poole et al., 2013), and serum IgG levels against Eubacterium nodatum and Actinomyces naeslundii, two common periodontal bacterial species, were higher in $\mathrm{AD}$ patients compared to healthy controls (Noble et al., 2014). A more recent study from Dominy et al. detected $P$. gingivalis and associated virulence proteins called gingipains (RgpB) in the brains and CSF of AD patients. In mice orally infected with $P$. gingivalis, this same group found $P$. gingivalis in $8 / 8$ brains and observed higher levels of the AD marker $\mathrm{A} \beta_{1-42}$ in these infected animals (Dominy et al., 2019). Repeated oral application of $P$. gingivalis by Ilievski et al. also led to detection of gingipain in/at brain cells and higher levels of several important inflammatory cytokines (IL-6, TNF- $\alpha$, IL-1 $\beta$ ) (Ilievski et al., 2018).

Additional studies have attempted to link periodontalassociated inflammation more generally to dysregulation of the CNS. In order to investigate the contribution of peripheral inflammatory responses on oxidative stress in the brain, Rokad et al. infected TNF- $\alpha$ transgenic mice with $P$. gingivalis. These mice express a stabilized version of TNF- $\alpha$ mRNA, resulting in overexpression of TNF- $\alpha$ protein in most tissues, including the brain (Rokad et al., 2017). In these mice, P. gingivalis infection increased the proportion of oxidized proteins in whole brain lysates, suggesting that $P$. gingivalis may contribute to cellular damage and downstream protein oxidation. In another series of mouse infections, Ding et al. orally infected young (4 week) and middle-aged (12 month) C57BL/6 mice with $P$. gingivalis and tested their learning and memory abilities 6 weeks after infection (Ding et al., 2018). They reported that only middleaged, $P$. gingivalis-infected mice showed poor performance in a Morris water maze test, while young $P$. gingivalis-infected and all uninfected mice performed equally well. Middle-aged infected mice also exhibited higher levels of pro-inflammatory cytokines (TNF- $\alpha$, IL- 6 and IL-1 $\beta$ ) in brain tissue, which is consistent with advanced age being a major risk factor for neurodegenerative diseases. These experiments, when coupled with patient studies, begin to suggest a complicated interplay between periodontal bacteria, neuroinflammation, and CNS dysfunction.

\section{Borrelia burgdorferi}

The ability of spirochetes to infiltrate the brain and cause disease has been well documented in the case of Treponema palladium, the causative agent of syphilis and associated neuropsychiatric disorders (Tuddenham and Ghanem, 2018). Less well-understood is how another spirochete, B. burgdorferi, the causative agent of Lyme disease, impacts the CNS. $B$. burgdorferi is a motile, microaerophilic, extracellular bacterium transmitted to humans by a tick vector. Containing a thin outer membrane that lacks LPS, B. burgdorferi is considered neither gram-negative nor gram-positive. Despite its unusual outer membrane, TLR2 has been implicated in sensing $B$. burgdorferi lipoproteins like OspA, and mice lacking TLR2 have increased bacterial loads (Alexopoulou et al., 2002; Wooten et al., 2002). Activation of innate immune sensing by OspA and other pathogen-associated molecular patterns induces expression of pro-inflammatory products like IL-6, TNF- $\alpha$, and nitric oxide (NO), as well as immunosuppressors like IL-10 (Chung et al., 2013). Because B. burgdorferi is primarily extracellular, B cell responses and antibodies help limit disease and pathogenesis. However, the bacterium has evolved ways to evade neutralizing antibodies, including expression of variable surface antigens and 
trafficking to the joints and skin where they may be inaccessible to circulating antibodies (Tilly et al., 2008).

Although the precise mechanisms through which Borrelia crosses the BBB remain unclear, the detection of Borrelia in CSF is well-documented using both PCR and culture methods (Wilske et al., 2007). CNS dysfunction associated with Borrelia, often referred to as Lyme neuroborreliosis, occurs during the disseminated stage of the disease and can involve both the central and peripheral nervous system. Curiously, European strains of Borrelia are more prone to cause Lyme neuroborreliosis, while North American isolates are more associated with Lyme arthritis, pointing to distinct virulence determinants or comorbidities that influence disease outcomes (Cardenas-de la Garza et al., 2019). Symptoms of neuroborreliosis (e.g., nerve pain, headache, facial nerve palsy) are generally inconsistent with neurodegenerative disorders, and Lyme neuroborreliosis itself is not associated with neurodegenerative disease. However, there is some, albeit circumstantial, evidence to suggest an association between $\mathrm{AD}$ and the presence of Borrelia in the brain or CSF.

A case study in 1987 was the first to successfully culture B. burgdorferi from brain tissue of a dementia patient with probable early stage AD (MacDonald and Miranda, 1987). More recent studies have detected nucleic acid or antigen evidence of Borrelia spirochetes in the CSF, blood, and cerebral cortex of $14 \mathrm{AD}$ patients, while 13 healthy controls were all negative. In three of these cases, Borrelia spirochetes were successfully cultured from the brains of post-mortem AD patients (Miklossy et al., 2004). Miklossy et al. have also observed AD-associated neurofibrillary tangles that immunoreact with anti-B. burgdorferi antibodies and co-localization of Borrelia antigens with $A \beta$ plaques (Miklossy et al., 2004). However, the results of these studies are still being debated, as other groups have been unable to detect Borrelia in AD patients' brains using PCR (Marques et al., 2000).

Nonetheless, additional animal and in vitro studies have provided support for a link between Borrelia and AD. In mouse experiments, labeled lipoproteins from the spirochete Borrelia turicatae were detected in the CNS after infection, and proinflammatory cytokines were detectable in the brain parenchyma, suggesting that circulating Borrelia-derived components may travel to the brain and cause neuroinflammation (Londoño and Cadavid, 2010). In ex vivo studies with CNS cells, exposure to $B$. burgdorferi spirochetes can induce $A \beta$ accumulation, tau phosphorylation, and increased A $\beta P P$ levels, all of which are characteristic of $\mathrm{AD}$ (Miklossy et al., 2006). How B. burgdorferi induces plaque-like phenomena in these cells is not completely understood. Spirochetes express a number of factors to facilitate their binding to host cells, and many of these factors (e.g., bacterial amyloids, fibronectinand collagen-binding proteins) can promote protein adhesion and coagulation, perhaps precipitating these $\mathrm{AD}$-like features. Alternatively, it is possible that sensing of spirochetes, or spirochete components, in the brain by resident microglial cells via TLRs and subsequent innate immune activation contributes to neuroinflammation.

\section{MYCOBACTERIAL INFECTION AND PD: A CASE STUDY IN COMMON MOLECULAR MECHANISMS DRIVING BACTERIAL PATHOGENESIS AND NEURODEGENERATIVE DISEASE}

\section{$M$. leprae and M. tuberculosis}

M. tuberculosis is a non-motile intracellular bacterium that replicates within alveolar macrophages and, during active infection, causes a devastating lung disease. Patients with active M. tuberculosis infection present with a pro-inflammatory type I IFN signature, and mice treated with recombinant IFN- $\beta$ succumb to disease faster than littermate controls (Manca et al., 2001). Likewise, mice lacking the type I IFN receptor (IFNAR) are protected (Stanley et al., 2007; Mayer-Barber et al., 2014), and mutations in IFNAR in human populations also confer resistance to M. tuberculosis (Zhang et al., 2018).

Although it is currently the number one infectious disease killer on earth, $M$. tuberculosis only kills a small number of patients it infects $(<1 \%)$. In the vast majority of cases, M. tuberculosis establishes a latent, subclinical infection that can persist for decades. We are only starting to appreciate how the immune system is engaged during latent tuberculosis. Increasingly, research suggests that $M$. tuberculosis is not completely dormant and instead undergoes repeated bursts of replication (Lin and Flynn, 2010). This "percolating" phenotype and its associated cycles of inflammation may impact multiple organ systems, including the CNS, over the lifetime of a patient.

A recent nationwide, population-based cohort study investigating the association between TB and PD purported that patients with TB had a 1.38-fold higher risk of PD compared to the general population (Shen et al., 2016). Conversely, vaccination with neuronal antigen in complete Freund's adjuvant (which contains heat-inactivated M. tuberculosis) or vaccination with the tuberculosis vaccine strain Bacilli Calmette-Guerin (BCG) each partially protected against $\mathrm{PD}$-associated neuronal death and prevented microglial activation in the MPTP mouse model of PD (Yong et al., 2011). Together, these data suggest that the immune response to $M$. tuberculosis may trigger or exacerbate CNS dysfunction.

A surprising number of connections between mycobacterial infection and genes associated with neuronal health have recently emerged. Notably, SNPs in several genes, namely LRRK2, PARK2, and PINK1 confer susceptibility to both mycobacterial infection and PD. Genome wide association studies identified these SNPs based on their association with Mycobacterium leprae, the causative agent of leprosy. M. leprae shares almost all of its genes with M. tuberculosis, although it causes distinct pathologies affecting primarily the nerves, skin, and nasal mucosa (Serrano-Coll et al., 2018). The bacterium mainly replicates within macrophages and peripheral nerve cells called Schwann cells. Depending on the host immune response, $M$. leprae causes a spectrum of disease. On one end, patients that develop a strong Th1 response are said to have tuberculoid disease and experience less severe symptoms and 
clear the bacilli. On the other end of the spectrum, patients with lepromatous disease mount a Th2 response and have high bacterial loads in the skin and nerves accompanied by severe tissue damage (Desvignes and Ernst, 2013). Because Th1/Th2 polarization of the adaptive immune responses is crucial for controlling $M$. leprae pathogenesis, studies frequently identify immune-associated loci (NOD2, TNFSF15, RIPK2, $I L 12 B$ ) as leprosy susceptibility determinants (Zhang et al., 2009; Marcinek et al., 2013; Teles et al., 2013). Less clear is why SNPs in PD-associated genes, typically studied in the context of mitochondrial homeostasis in neurons, also confer susceptibility to leprosy. Here, using $M$. tuberculosis and $M$. leprae as case studies, we will explore how molecular connections between PD-associated genes and bacterial pathogenesis may unexpectedly shed light on mechanisms of neuroinflammation and neurodegeneration.

\section{Selective Autophagy of Bacteria (Xenophagy) and Mitochondria (Mitophagy) Are Functionally Parallel Pathways}

To date, three $\mathrm{PD}$-associated genes have been repeatedly implicated in mycobacterial susceptibility: LRRK2, PARK2, and PINK1. The proteins encoded by each of these genes have been shown to be important for mitochondrial homeostasis and turnover, which are controlled by a general process known as autophagy. Autophagy is an evolutionarily conserved process in eukaryotes whereby cytosolic components are enveloped and sequestered in double membrane structures that fuse with and are degraded in lysosomes. In response to nutrient limitation, such as amino acid starvation, general autophagy serves a catabolic function by degrading organelles and other cellular components in order to generate substrates for energy metabolism and new protein synthesis. A related process termed selective autophagy renovates the cytosol by specifically tagging damaged organelles and protein aggregates with ubiquitin (colloquially referred to as an "eat me" signal) for their removal. Selective autophagy can mediate turnover of damaged organelles, like mitochondria, in a process known as mitophagy. Selective autophagy also plays an important role in innate immune defense against invading intracellular pathogens, by tagging cytosolically exposed bacteria with ubiquitin and targeting them to autophagosomes (a.k.a. xenophagy).

Multiple studies have shown that macrophages use selective autophagy to tag and target a population ( 30\%) of $M$. tuberculosis bacilli to autophagosomes. These events depend on permeabilization of the $M$. tuberculosis phagosome, which requires the activity of the pathogen's ESX-1 virulence-associated secretion system. As a result of phagosomal permeabilization, the cytosolic DNA sensor cGAS detects bacterial dsDNA and elicits the potent pathologic type I IFN immune response via the cGAS/STING/TBK1/IRF3 signaling pathway (Collins et al., 2015; Wassermann et al., 2015; Watson et al., 2015). Work by Watson et al., demonstrated that $M$. tuberculosis-derived dsDNA also plays an critical role in triggering xenophagy through cGAS/STING, which is required for recruitment of downstream autophagy markers like p62 (Watson et al.,
2012, 2015). Other selective autophagy adapters have also been shown to localize to the $M$. tuberculosis phagosome, including NDP52, and NRB1, although it remains unclear whether any of these are absolutely required for autophagosomal targeting or if there is built in redundancy in the repertoire of selective adapters in macrophages. Because evolutionarily, mitochondria were once themselves intracellular bacteria bound by a membrane, it is perhaps not surprising that cells employ similar machinery to sense and clear damaged mitochondria (Manzanillo et al., 2013; West et al., 2015; West and Shadel, 2017). However, as these connections are still new, many questions regarding the parallels between xenophagy and mitophagy persist. We do not fully understand what can serve as "danger signals" to trigger xenophagy and/or mitophagy, and we have a poor understanding of how cells tag these different cargos (bacteria vs. mitochondria) for destruction (e.g., ubiquitinated substrates, sensing molecules, autophagy adaptors, etc). Moreover, the degree to which these pathways share machinery and regulatory components remains unclear. Parallels and differences between mitophagy and xenophagy are illustrated in Figure 2.

\section{PINK1, Parkin, and LRRK2 in Mitophagy and PD}

Numerous lines of evidence suggest that mitochondrial dysfunction plays a pivotal role in PD. Several mutations linked to PD (PINK1, PARK2, LRRK2) affect proteins with critical and well-characterized roles in mitophagy (Table 1). Mitophagy is active in healthy cells to maintain mitochondrial homeostasis but is upregulated in response to various stressors to clear mitochondria that have sustained damage.

Several mechanistic pathways of mitophagy have been described. Most studied is the ubiquitin-dependent mitophagy pathway. When mitochondria are depolarized and cannot import proteins, the kinase PINK1 accumulates on the outer membrane of the mitochondria where it recruits the E3 ligase Parkin (encoded by PARK2). PINK1 phosphorylates both Parkin and ubiquitin, activating Parkin to ubiquitinate proteins on the surface of compromised mitochondria. This ubiquitination serves as an "eat me" signal to the cell, and recruits cargo receptors (OPTN, NDP52, p62, and NBR1), which bind to both ubiquitin and the core autophagy protein family LC3. This results in recruitment of the isolation membrane and engulfment of the damaged mitochondrial cargo within an autophagosome. Interestingly, Szargel et al. demonstrated that SIAH, another E3 ubiquitin ligase, is capable of tagging mitochondria with this "eat me" signal, suggesting that E3 ligases in addition to Parkin can participate in ubiquitin-mediated mitophagy (Szargel et al., 2016).

Another mechanism of mitophagy, which is independent of PINK1 and Parkin is called receptor-mediated mitophagy and utilizes transmembrane proteins located on the outer membrane of mitochondria. These transmembrane receptors (Nix/Bnip3, Bnip3, FUNDC1, FKBP8) bind to LC3 proteins as well as the closely related GABARAP proteins to directly recruit autophagosomal membranes. Finally, cardiolipinmediated mitophagy occurs when cardiolipin, a phospholipid normally found on the inner mitochondrial membrane, is 


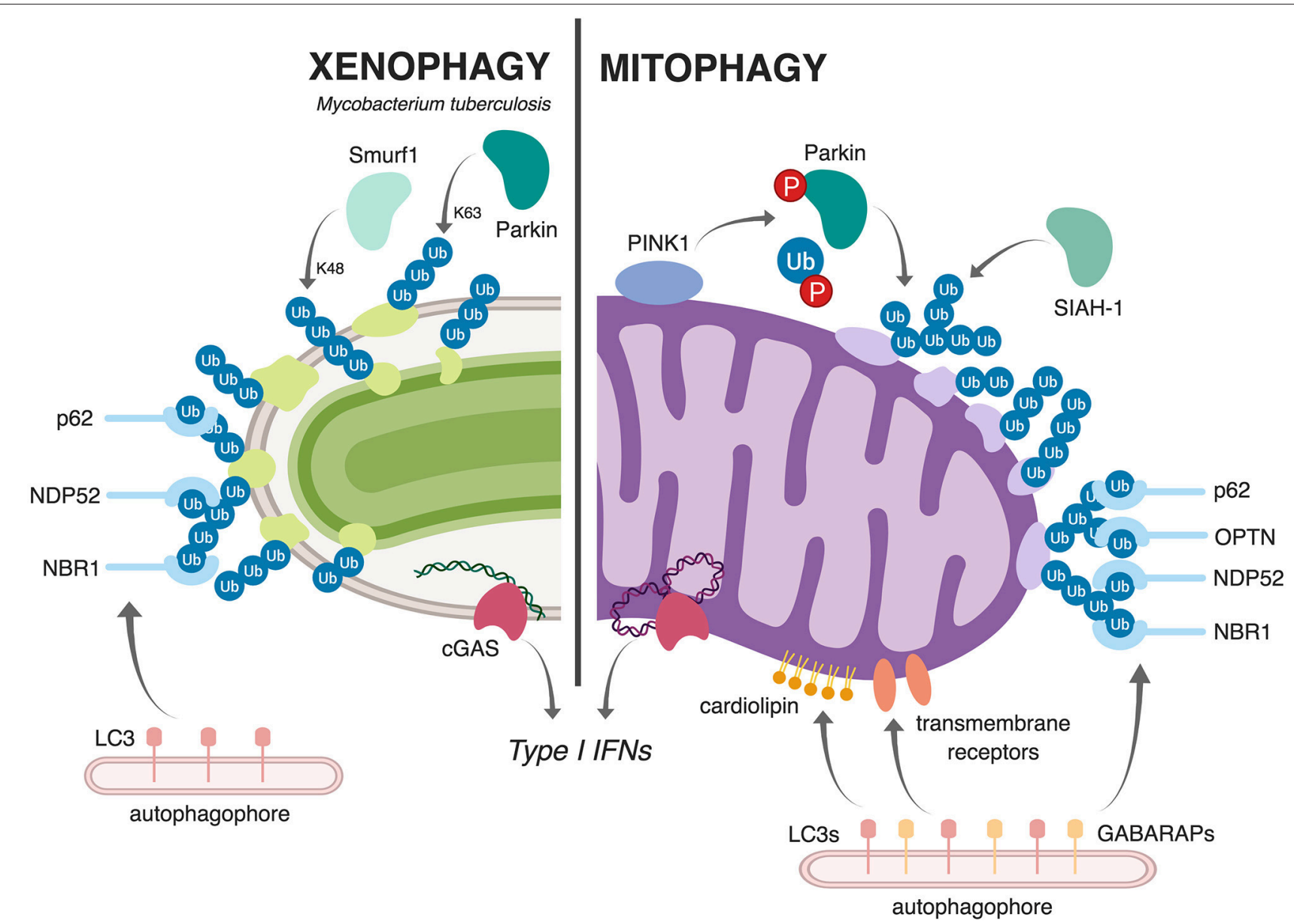

FIGURE 2 | Schematic representation comparing and contrasting mitophagy and xenophagy of Mtb. During xenophagy of Mtb in macrophages (left), Mtb-containing vacuoles are decorated with ubiquitin via the E3 ligases Parkin (Watson et al., 2012) and Smurf1 (Franco et al., 2017). This recruits various selective autophagy adaptors (p62, NDP52, and NBR1) and, subsequently, LC3 and the autophagophore. Upon mitochondrial damage (right), the kinase PINK1 phosphorylates both Parkin and ubiquitin (Kondapalli et al., 2012; Kane et al., 2014; Koyano et al., 2014; Kazlauskaite and Muqit, 2015), allowing Parkin to ubiquitinate mitochondrial proteins. The E3 ligase SIAH1 also contributes to the ubiquitination of mitochondrial proteins (Szargel et al., 2016). As in xenophagy, this ubiquitination recruits selective autophagy adaptors (p62, OPTN, NDP52, and NBR1), LC3, and the autophagophore. Other ubiquitin-independent mechanisms, like cardiolipin-dependent mitophagy and receptor-mediated mitophagy, can also target damaged mitochondria to autophagy; in these pathways, exposed cardiolipin or outer membrane proteins directly recruit LC3 proteins or the closely related GAPARAP proteins. Both Mtb infection and mitochondrial damage activate the cytosolic DNA sensor cGAS (bottom), which elicits a type I IFN transcriptional program (Wassermann et al., 2015; Watson et al., 2015; West et al., 2015; Franco et al., 2017). Figure created with BioRender.

transported to the outer mitochondrial membrane by PLS3 (phospholipid scramblase-3) and hexameric NDPK-D in responses to various types of mitochondrial damage (Chu et al., 2013; Kagan et al., 2016). Once there, cardiolipin serves as another "eat me" signal and is bound directly by LC3 to recruit autophagosomal membranes. Chu et al. found that induction of this pathway is especially robust when neurons are treated with PD-related mitophagy stressors (rotenone, staurosporine, 6-hydroxydopamine), which bolsters the physiological relevance of this pathway in PD progression and further highlights that different cell types and different forms of mitochondrial damage can influence mitophagy. To date, neither receptormediated mitophagy nor cardiolipin-mediated mitophagy have been shown to influence bacterial survival or replication in host cells.
The association between PD and gene mutations in mitochondrial quality control pathways has long implied a connection between mitophagy and PD. Gene associations are further supported by patient studies suggesting that environmental toxins that induce mitochondrial stress (such as rotenone, paraquat, MPTP, and other organic chemicals) can increase the risk of sporadic PD. Additionally, age is the largest risk factor for PD, suggesting that accumulation of cellular damage plays a critical role in disease progression and defects in neuronal mitophagy are generally accepted as contributing to $\mathrm{PD}$ onset and/or exacerbation. Indeed, neurons have extremely high energy demands in order to maintain ion gradients required for neurotransmission. Since their energy is produced primarily through oxidative respiration, they rely on functional and healthy mitochondria, and dysregulated mitochondrial networks 
TABLE 1 | Genes associated with susceptibility with to mycobacterial infection and Parkinson's Disease.

\begin{tabular}{|c|c|c|c|c|}
\hline Gene & Relationship to PD & $\begin{array}{l}\text { Role in mitochondrial } \\
\text { homeostasis }\end{array}$ & $\begin{array}{l}\text { Reported roles in infection and } \\
\text { immunity }\end{array}$ & $\begin{array}{l}\text { Implicated in these bacterial } \\
\text { infections }\end{array}$ \\
\hline LRRK2 & $\begin{array}{l}\text { Most common genetic } \\
\text { cause of PD; } \\
\text { responsible for } 2 \% \text { of } \\
\text { total PD cases }\end{array}$ & $\begin{array}{l}\text { - Important regulation of } \\
\text { mitochondrial fission and } \\
\text { fusion (possibly though } \\
\text { phosphorylation of RAB7) } \\
\text { (Beilina et al., 2014) } \\
\text { - Mutants associated with } \\
\text { increased susceptibility to } \\
\text { oxidative stress and } \\
\text { decreased antioxidant } \\
\text { defenses (Angeles et al., 2014) } \\
\text { - Mutations can activate or } \\
\text { inhibit autophagy (Giaime } \\
\text { et al., 2017; Mamais et al., } \\
\text { 2018) } \\
\text { - Can physically interact with } \\
\text { Parkin (Smith et al., 2005) }\end{array}$ & $\begin{array}{l}\text { - Upregulated in response to IFN-y } \\
\text { (Gardet et al., 2010) } \\
\text { - Exogenous expression increases } \\
\text { activation of NFkB (Gardet et al., 2010) } \\
\text { - } \text { Required to control S. Typhimurium } \\
\text { replication in RAW264.7 cells (Gardet } \\
\text { et al., 2010) } \\
\text { - Negative regulator of NFAT (nuclear } \\
\text { factor of activated T cells) (Liu et al., } \\
\text { 2011) } \\
\text { - Systemic LPS treatment of } \\
\text { LRRK2-mutant mice results in neuronal } \\
\text { loss (Schildt et al., 2019) } \\
\text { - Negative regulator of phagosome } \\
\text { maturation in macrophages during M. } \\
\text { tuberculosis infection (Härtlova et al., } \\
\text { 2018) } \\
\text { - Promotes activation of the NLRC4 } \\
\text { inflammasome during S. Typhimurium } \\
\text { infection (Liu et al., 2017) }\end{array}$ & $\begin{array}{l}\text { - Mycobacterium leprae (Zhang et al., } \\
\text { 2009; Marcinek et al., 2013; Wang et al., } \\
\text { 2016) } \\
\text { - Mycobacterium tuberculosis (Härtlova } \\
\text { et al., 2018), } \\
\text { - Salmonella enterica serovar } \\
\text { Typhimurium (Liu et al., 2017) }\end{array}$ \\
\hline $\begin{array}{l}\text { PARK2 } \\
\text { (Parkin) }\end{array}$ & $\begin{array}{l}\text { Mutations cause } 15 \% \\
\text { of familial and } 4 \% \text { of } \\
\text { sporadic PD cases with } \\
\text { onset before } 40 \text { years } \\
\text { of age Patients with } \\
\text { PARK2 mutations show } \\
\text { defects in } \\
\text { mitochondrial } \\
\text { quality control }\end{array}$ & $\begin{array}{l}\text { - Promotes mitophagy by } \\
\text { ubiquitinating proteins on the } \\
\text { outer membrane of } \\
\text { mitochondria } \\
\text { following damage/depolarization }\end{array}$ & $\begin{array}{l}\text { - Important for controlling M. tuberculosis } \\
\text { replication in macrophages and in mice, } \\
\text { and controlling M. marinum and S. } \\
\text { Typhimurium in Drosophila.(Manzanillo } \\
\text { et al., 2013) } \\
\text { - Loss of PARKIN misregulates immune } \\
\text { gene expression in Drosophila (Greene } \\
\text { et al., 2005) }\end{array}$ & $\begin{array}{l}\text { - Mycobacterium leprae (Mira et al., 2004) } \\
\text { - Mycobacterium tuberculosis (Manzanillo } \\
\text { et al., 2013) } \\
\text { - Salmonella Typhi (Manzanillo et al., } \\
\text { 2013) }\end{array}$ \\
\hline PINK1 & $\begin{array}{l}\text { Mutations increase risk } \\
\text { of early onset PD } \\
\text { Patients with PINK1 } \\
\text { mutations show } \\
\text { defects in } \\
\text { mitochondrial } \\
\text { quality control }\end{array}$ & $\begin{array}{l}\text { - Involved in activation of } \\
\text { mitophagy via phosphorylation } \\
\text { of Parkin (Kim et al., 2008; } \\
\text { Gladkova et al., 2018) } \\
\text { - Can also mediate } \\
\text { Parkin-independent mitophagy } \\
\text { (Villa et al., 2018) }\end{array}$ & 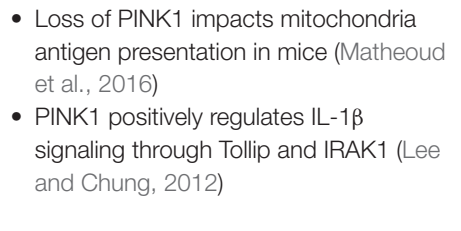 & $\begin{array}{l}\text { - Mycobacterium leprae (Wang et al., } \\
\text { 2016) }\end{array}$ \\
\hline
\end{tabular}

For each gene (LRRK2, PARK2, and PINK1), their relationship to PD, role in mitochondrial health, reported roles in infection and immunity, and associated bacterial infections are described.

lead to cell death and neuronal defects (Kann and Kovács, 2007). These defects and failure of quality control likely lead to the neuronal loss in the SNc observed in the brains of PD patients.

Mutations in PINK1 and PARK2 are the most frequently observed in patients with familial or inherited PD, and PARK2 mutations are the most common mutation associated with early-onset PD. Loss-of-function mutations in PINK1 or PARK2 create a block in mitophagy, resulting in accumulation of damaged and dysfunctional mitochondria. Consistent with these observations, an early study by Zhu et al. showed that mitochondria-containing autophagosomes accumulate in the substantia nigra of PD patients (Kann and Kovács, 2007). Fiesel et al. later showed that there is also a marked increase in phospho-ubiquitin in the substantia nigra of PD patients (Zhu et al., 2003). Accumulation of this PINK1/Parkin-dependent mitophagy marker strongly suggests a pathologic block in this mitophagy pathway as the marked cargo fails to be degraded. However, PINK1 and Parkin also have regulatory roles in the biogenesis of mitochondria via PARIS and PGC1-alpha, so mutations in PINK1 or PARK2 could contribute to mitochondrial dysfunction by preventing the replacement of mitochondria (Fiesel et al., 2015).

\section{M. tuberculosis and Parkin}

In order for M. tuberculosis to be destroyed via xenophagy, it must be targeted with ubiquitin chains. A ubiquitin "cloud" is associated with $\sim 30 \%$ of intracellular M. tuberculosis bacilli and consists of at least K63- and K48-linked ubiquitin species, suggesting multiple protein substrates are modified with ubiquitin (Manzanillo et al., 2013). Presently, the identity of these protein substrates remains unclear, and there is great interest in illuminating whether ubiquitin chains are conjugated to recruited host signaling proteins or to exposed M. tuberculosis surface proteins, or perhaps to both. Similarly, the precise identities of ubiquitinated proteins around damaged mitochondria remain unknown.

Although the nature of ubiquitin targets remains elusive, several groups have identified E3 ubiquitin ligases that play a role in targeting $M$. tuberculosis-phagosomes to xenophagy, including 
Parkin and Smurf1. In bone marrow derived macrophages, Parkin deficiency coincided with significant decreases in the K63-linked ubiquitin "cloud" around M. tuberculosis (Manzanillo et al., 2013). Loss of Parkin also resulted in decreased recruitment of downstream selective autophagy adapters including p62, NBR1, and NDP52. Importantly, $M$. tuberculosis replication was enhanced in both $P A R K 2^{-/-}$macrophages and in PARK2 knockdown human monocyte U937 cells, and PARK2 $2^{-/-}$mice had significantly higher bacterial burdens in their lungs, livers, and spleens compared to wild-type controls. Along these same lines, genome-wide association studies have identified alleles of PARK2 that increase susceptibility to M. leprae (Mira et al., 2004) although the role of xenophagy in controlling M. leprae is currently unknown. Susceptibility alleles of Parkin have also been found for Salmonella Typhi and paratyphi infection (Ali et al., 2006), the causes of typhoid and paratyphoid fever, respectively, which supports a broad role for Parkin in controlling intracellular pathogens (Table 1).

In a recent paper, Franco et al. showed that the E3 ligase Smurf1 is also required for targeting M. tuberculosis to xenophagy. Smurf1 $1^{-/-}$macrophages were defective in recruiting K48-linked polyubiquitin and NBR1 to M. tuberculosisassociated phagosomes, and loss of Smurf1 led to increased bacterial loads ex vivo in macrophages and in vivo in mice (Franco et al., 2017). Interestingly, Smurf1 has no known role in mitophagy and is only linked to PD by studies examining LPS-induced neuroinflammation, where loss of Smurf1 inhibited neuronal necroptosis in the CNS (Shao et al., 2018). This suggests that certain E3 ubiquitin ligases like Smurf1 may play a privileged role in autophagy following microbial-induced damage and/or inflammation. Together, these data point to critical roles for E3 ligases like Parkin in controlling bacterial replication ex vivo and in vivo and strongly suggest that human mutations in PARK2 confer susceptibility to intracellular bacterial pathogens because of defects in ubiquitin-mediated targeting. However, additional roles for Parkin in regulating other immune-relevant cellular pathways can not be discounted.

\section{M. tuberculosis and LRRK2}

LRRK2 is a large, multi-functional protein, and as such, has many possible roles in regulating mitochondrial dynamics to influence PD pathogenesis. Mutations in this gene occur in both sporadic and familial cases of PD, and it is the most common PD-linked autosomal dominant mutation. Activating mutations in LRRK2 like G2019S and R144C are common in PD patients, so these mutants have been studied extensively. Such mutations have been shown to increase mitophagy in neuronal cells, which leads to decreased mitochondrial mass, dendrite retraction, and neuronal dysfunction (Cherra et al., 2013). Wang et al. showed that constitutively active LRRK2 mutants exhibit prolonged interactions with Drp1, which promotes mitochondrial fragmentation (Wang et al., 2012), and Hsieh et al. showed that constitutively active LRRK2 mutants are defective in forming a complex with Miro, a protein that anchors mitochondria to microtubules. In the absence of a LRRK2/Miro complex, Miro is stabilized, mitochondria movement proceeds and mitophagy is significantly delayed (Hsieh et al., 2016).
A 2009 New England Journal of Medicine study found that SNPs in LRRK2 are associated with susceptibility to infection with M. leprae (Zhang et al., 2009). Subsequent studies have identified a panel of LRRK2-associated SNPs that associate with leprosy outcome (Wang et al., 2015). A recent report from Harlova et al. showed that loss of LRRK2 $\left(\operatorname{Lrkk} 2^{-/-}\right)$enhanced phagosomal maturation in macrophages, resulting in reduced $M$. tuberculosis replication (Härtlova et al., 2018). In vivo, loss of LRRK2 caused a moderate decrease in M. tuberculosis bacterial loads in the lung and spleen of infected mice at early time points. Increased control of $M$. tuberculosis replication correlated with increased expression of several anti-bacterial cytokines (TNF- $\alpha$, IFN- $\gamma$ ) and lower expression of pro-bacterial IFN- $\alpha$, although these cytokine differences were seemingly transient. The authors proposed that loss of LRRK2 enhances $M$. tuberculosis phagosomal maturation, but how these cell-intrinsic differences translate to enhanced innate immune cytokine expression remains unclear. Surprisingly, the authors found no LRRK2dependent changes to xenophagy of $M$. tuberculosis, despite a number of reports linking LRRK2 to mitochondrial turnover in other cell types (Manzoni, 2012). Curiously, Harlova et al. also reported that macrophages harboring the PD-associated G2019S gain-of-function LRRK2 mutation supported higher levels of M. tuberculosis growth. The differing involvement of LRRK2 in xenophagy vs. mitophagy could be due to cell-specific LRRK2 functions or unknown differences between targeting of bacterial pathogens vs. damaged mitochondria (for example, ubiquitinmediated vs. receptor- or cardiolipin-mediated). Together, these studies imply an important but complex role for LRRK2 in controlling intracellular M. tuberculosis replication as well as in regulating systemic immune responses and inflammation during infection (Table 1).

\section{M. tuberculosis and PINK1}

Based on GWAS studies showing association between SNPs in $L R R K 2$ and mycobacterial infection, the same group looked for SNPs in other mitochondrial/PD-associated genes including PINK1. In their study of Han Chinese from South China, Wang et al. reported PINK1 SNP rs4704 was associated with increased susceptibility to leprosy (Wang et al., 2016; Table 1).

The mechanism by which PINK1 impacts leprosy susceptibility remains a mystery and to date, no one has reported on the requirement for PINK1 in controlling $M$. tuberculosis infection. It is possible that PINK1 plays a direct role in initiating the tagging and targeting of damaged $M$. tuberculosis and/or $M$. leprae-phagosomes to xenophagy, mirroring its role in mitophagy. It is also conceivable that PINK1, along with Parkin and LRRK2, plays important indirect roles in regulating innate immune responses to mycobacterial infection. For example, accumulation of damaged mitochondria can increase levels of ROS and induce low-level activation of type I IFN expression downstream of cytosolic DNA sensing of mtDNA leaked from damaged mitochondria (West et al., 2015). Because type I IFN levels in large part dictate the outcome of M. tuberculosis infection, it is likely that maintaining healthy mitochondria in immune cells is important for controlling bacterial pathogenesis in the periphery. Therefore, discovering 
precisely how these $\mathrm{PD}$-associated genes contribute to both cell-intrinsic and inflammatory responses will expand our understanding of how immune responses to bacterial infection might lead to neurodegeneration.

\section{Neuroinflammation, Bacterial Infection, and Neurodegeneration: Outstanding Questions}

Discerning correlation from causation is the major hurdle in defining a role for infection in triggering neurodegeneration. It is impossible to control or prevent human exposure to pathogens, and many infections are ubiquitous in the population. Therefore, concluding that a specific infection precipitates a particular neurodegenerative disease is almost impossible. The odds are that most $\mathrm{PD}, \mathrm{AD}$, and $\mathrm{MS}$ patients will have been exposed to a number of the bacterial pathogens reviewed here, as well as viral pathogens associated with neurodegenerative diseases, over the course of a lifetime. A recent epidemiological study tested this "multiple microbe" hypothesis and indeed reported that $\mathrm{PD}$ risk was increased in individuals who were seropositive for five or six of the pathogens queried (CMV, EBV, HSV1, B. burgdorferi, C. pneumoniae, and H. pylori), compared to healthy controls. The emerging idea that mutations associated with CNS dysfunction may themselves impact susceptibility to infection further exacerbates this already complex "chicken or egg" conundrum.

Looking to the future, our best bets for studying the role of bacterial pathogens in neuroinflammation and neurodegenerative diseases are likely animal models of infection and controlled cellular studies. A number of pathogens described here, including B. burgdorferi, Mycobacterium tuberculosis, and $H$. pylori, have well-established mouse models of infection that mimic human disease in many ways. By combining bacterial and mouse genetics, we might begin to tease apart whether a.) bacterial pathogens themselves directly mediate CNS damage, b.) immune responses to bacterial infection mediate CNS damage, and/or c.) CNS mutations or CNS dysfunction influence susceptibility to bacterial infection. For example, infections could be performed in knockout mice that lack key immune receptors/cytokines to distinguish bacteria- vs. immune-related CNS phenotypes. Such immune receptor mutations could be targeted to specific cell types (e.g., macrophages, microglia, neurons) to distinguish how cells in the periphery vs. cells in the brain contribute to neuroinflammation. Likewise, bacterial mutants lacking key virulence factors could be used to modulate distinct outcomes in terms of tissue damage, dissemination, and immune outcomes. Infections could also be performed in wildtype mice alongside mice predisposed to certain CNS disorders or mice with mitochondrial defects to simulate a "multiple-hit" scenario. Ideally, groups that have expertise in both bacterial pathogenesis and neuroinflammation will undertake these experiments so that conditions that best mimic human disease can be maintained (e.g., natural routes of inoculation and low-dose inoculum).

Cellular studies allow for further control over experimental variables compared to animal models but carry many caveats.
Previous approaches have depended on overexpression of key proteins, non-physiological methods of mitochondrial damage, and monocultures of cell types with varying in vivo relevance. Many of these studies have reported conflicting observations depending on cell type and experimental conditions. Indeed, it is difficult to mimic human disease conditions in vitro with cellular conditions, since physiologic stresses are subtler and occur sometimes repeatedly over many decades of life. Moving forward, it will be important to investigate how mutations in PD-associated genes impact mitochondrial health, gene expression, and the metabolic state of not only neurons but also cell types in the periphery, such as macrophages, T cells, B cells, etc.

Along these lines, there are many outstanding questions regarding how factors related to mitophagy and xenophagy impact bacterial pathogenesis and neurodegeneration. For some time, researchers have been puzzled by the lack of overt PD phenotypes in mice harboring mutations in $\mathrm{PD}$-associated genes. Recently, Pickrell et al. found that Parkin knockout coupled with mitochondrial DNA stress precipitated PD symptoms (Pickrell et al., 2015), and Sliter et al. showed that PINK1 knockout combined with exhaustive exercise or mitochondrial DNA stress induced PD-like phenotypes. Interestingly, loss of STING rescued the PD symptoms, indicating type I IFN-related inflammation plays a key role in this process (Sliter et al., 2018). Together, these studies provide experimental support for the multiple-hit hypothesis, and imply that patients with mutations in PD-linked genes need an additional stressor, such as inflammation, to trigger PD progression (Newman and Shadel, 2018). If this type of PD-associated mitochondrial damage is precipitated in an immune cell like a macrophage, one would expect dysregulation of innate immune gene expression, as mtDNA is a known agonist of cytosolic DNA sensors and the type I IFN response (West et al., 2015; West and Shadel, 2017). Consistent with this idea, mutations in LRRK2 have been shown repeatedly to impact innate immune gene expression in macrophages ex vivo and control caspase-1 activation and IL-1 $\beta$ secretion via the NLCR4 inflammasome (Liu et al., 2017). Such dysregulation of the innate immune response could be a consequence of prolonged pathogen sensing and/or mitochondrial damage and mtDNA leakage, both of which would result from defects in mitophagy/xenophagyrelated pathways.

Future work should build upon these exciting new perspectives so that we might fully uncover the molecular mechanisms that drive CNS changes during infection. Such discoveries will identify infection-dependent biomarkers that can be correlated with disease outcomes and open the door for novel immune-targeted therapeutic interventions designed to halt or slow neurodegenerative disease progression.

\section{AUTHOR CONTRIBUTIONS}

$\mathrm{KP}$ conceived the structure and content of the manuscript. $\mathrm{KP}, \mathrm{SB}$, and $\mathrm{CW}$ contributed content. KP, SB, and RW edited final manuscript. 


\section{FUNDING}

RW: NIH/NIAID 1R01AI125512 TRIM14 polarizes DNA sensing outcomes during the innate immune response to Mycobacterium tuberculosis. Michael J. Fox foundation for Parkinson's research 12185 validating

\section{REFERENCES}

Alexopoulou, L., Thomas, V., Schnare, M., Lobet, Y., Anguita, J., Schoen, R. T., et al. (2002). Hyporesponsiveness to vaccination with Borrelia burgdorferi OspA in humans and in TLR1- and TLR2-deficient mice. Nat. Med. 8, 878-884. doi: $10.1038 / \mathrm{nm} 732$

Ali, S., Vollaard, A. M., Widjaja, S., Surjadi, C., van de Vosse, E., and van Dissel, J. T. (2006). PARK2/PACRG polymorphisms and susceptibility to typhoid and paratyphoid fever. Clin. Exp. Immunol. 144, 425-431. doi: 10.1111/j.1365-2249.2006.03087.x

Anderson, P. J., Watts, H. R., Jen, S., Gentleman, S. M., Moncaster, J. A., Walsh, D. T., et al. (2009). Differential effects of interleukin-1 $\beta$ and S100B on amyloid precursor protein in rat retinal neurons. Clin Ophthalmol 3, 235-242. doi: 10.2147/OPTH.S2684

Angeles, D. C., Ho, P., Chua, L. L., Wang, C., Yap, Y. W., Ng, C., et al. (2014). Thiol peroxidases ameliorate LRRK2 mutant-induced mitochondrial and dopaminergic neuronal degeneration in Drosophila. Hum. Mol. Genet. 23, 3157-3165. doi: 10.1093/hmg/ddu026

Arellano, G., Ottum, P. A., Reyes, L. I., Burgos, P. I., and Naves, R. (2015). Stage-specific role of interferon-gamma in experimental autoimmune encephalomyelitis and multiple sclerosis. Front Immunol 6:492. doi: 10.3389/fimmu.2015.00492

Arking, E. J., Appelt, D. M., Abrams, J. T., Kolbe, S., Hudson, A. P., and Balin, B. J. (1999). Ultrastructural Analysis of Chlamydia pneumoniae in the Alzheimer's brain. Pathogenesis 1, 201-211.

Balin, B. J., Gérard, H. C., Arking, E. J., Appelt, D. M., Branigan, P. J., Abrams, J. T., et al. (1998). Identification and localization of Chlamydia pneumoniae in the Alzheimer's brain. Med. Microbiol. Immunol. 187, 23-42. doi: $10.1007 / \mathrm{s} 004300050071$

Beilina, A., Rudenko, I. N., Kaganovich, A., Civiero, L., Chau, H., Kalia, S. K., et al. (2014). Unbiased screen for interactors of leucine-rich repeat kinase 2 supports a common pathway for sporadic and familial Parkinson disease. Proc. Natl. Acad. Sci. U.S.A. 111, 2626-2631. doi: 10.1073/pnas.1318306111

Bell, J. S., Spencer, J. I., Yates, R. L., Yee, S. A., Jacobs, B. M., and DeLuca, G. C. (2018). Invited Review: From nose to gut - the role of the microbiome in neurological disease. Neuropathol. Appl. Neurobiol. 129, 154. doi: $10.1111 /$ nan. 12520

Beydoun, M. A., Beydoun, H. A., Elbejjani, M., Dore, G. A., and Zonderman, A. B. (2018). Helicobacter pylori seropositivity and its association with incident allcause and Alzheimer's disease dementia in large national surveys. Alzheimers Dement 14, 1148-1158. doi: 10.1016/j.jalz.2018.04.009

Braniste, V., Al-Asmakh, M., Kowal, C., Anuar, F., Abbaspour, A., Tóth, M., et al. (2014). The gut microbiota influences blood-brain barrier permeability in mice. Sci. Transl. Med. 6:263ra158. doi: 10.1126/scitranslmed.3009759

Brochard, V., Combadière, B., Prigent, A., Laouar, Y., Perrin, A., Beray-Berthat, V., et al. (2009). Infiltration of $\mathrm{CD}^{4+}$ lymphocytes into the brain contributes to neurodegeneration in a mouse model of Parkinson disease. J. Clin. Invest. 119, 182-192. doi: 10.1172/JCI36470

Browne, T. C., McQuillan, K., McManus, R. M., O’Reilly, J.-A., Mills, K. H. G., and Lynch, M. A. (2013). IFN- $\gamma$ Production by amyloid $\beta$-specific Th1 cells promotes microglial activation and increases plaque burden in a mouse model of Alzheimer's disease. J. Immunol. 190, 2241-2251. doi: 10.4049/jimmunol.1200947

Bu, X.-L., Yao, X.-Q., Jiao, S.-S., Zeng, F., Liu, Y.-H., Xiang, Y., et al. (2015). A study on the association between infectious burden and Alzheimer's disease. Eur. J. Neurol. 22, 1519-1525. doi: 10.1111/ene.12477

Cao, Y., Goods, B. A., Raddassi, K., Nepom, G. T., Kwok, W. W., Love, J. C., et al. (2015). Functional inflammatory profiles distinguish myelin-reactive the role of LRRK2 in responding to cytosolic DNA and damaged mitochondria. Michael J. Fox Foundation for Parkinson's Research M1801235. Investigating how PD-associated LRRK2 alleles and LRRK2 inhibitors influence the immune response and susceptibility to bacterial infection.
T cells from patients with multiple sclerosis. Sci. Transl. Med. 7:287ra74. doi: 10.1126/scitranslmed.aaa8038

Cardenas-de la Garza, J. A., De la Cruz-Valadez, E., Ocampo-Candiani, J., and Welsh, O. (2019). Clinical spectrum of Lyme disease. Eur. J. Clin. Microbiol. Infect. Dis. 38, 201-208. doi: 10.1007/s10096-018-3417-1

Carter, C. J. (2017). Genetic, transcriptome, proteomic, and epidemiological evidence for blood-brain barrier disruption and polymicrobial brain invasion as determinant factors in Alzheimer's disease. J. Alzheimers Dis. Rep. 1, 125-157. doi: 10.3233/ADR-170017

Carter, C. J., France, J., Crean, S., and Singhrao, S. K. (2017). The Porphyromonas gingivalis/host interactome shows enrichment in GWASdb genes related to Alzheimer's disease, diabetes and cardiovascular diseases. Front. Aging Neurosci. 9:408. doi: 10.3389/fnagi.2017.00408

Cekici, A., Kantarci, A., Hasturk, H., and Van Dyke, T. E. (2014). Inflammatory and immune pathways in the pathogenesis of periodontal disease. Periodontol 64, 57-80. doi: 10.1111/prd.12002

Chen, C.-K., Wu, Y.-T., and Chang, Y.-C. (2017). Association between chronic periodontitis and the risk of Alzheimer's disease: a retrospective, population-based, matched-cohort study. Alzheimers Res. Ther. 9:56. doi: 10.1186/s13195-017-0282-6

Chen, J.-H., Ke, K.-F., Lu, J.-H., Qiu, Y.-H., and Peng, Y.-P. (2015). Protection of TGF- $\beta 1$ against neuroinflammation and neurodegeneration in A $\beta 1$-42-induced Alzheimer's disease model rats. PLoS ONE 10:e0116549. doi: 10.1371/journal.pone.0116549

Cherra, S. J., Steer, E., Gusdon, A. M., Kiselyov, K., and Chu, C. T. (2013). Mutant LRRK2 elicits calcium imbalance and depletion of dendritic mitochondria in neurons. Am. J. Pathol. 182, 474-484. doi: 10.1016/j.ajpath.2012.10.027

Chu, C. T., Ji, J., Dagda, R. K., Jiang, J. F., Tyurina, Y. Y., Kapralov, A. A., et al. (2013). Cardiolipin externalization to the outer mitochondrial membrane acts as an elimination signal for mitophagy in neuronal cells. Nat. Cell Biol. 15, 1197-1205. doi: 10.1038/ncb2837

Chung, Y., Zhang, N., and Wooten, R. M. (2013). Borrelia burgdorferi elicitedIL-10 suppresses the production of inflammatory mediators, phagocytosis, and expression of co-stimulatory receptors by murine macrophages and/or dendritic cells. PLoS ONE 8:e84980. doi: 10.1371/journal.pone.0084980

Collins, A. C., Cai, H., Li, T., Franco, L. H., Li, X.-D., Nair, V. R., et al. (2015). Cyclic GMP-AMP Synthase Is an Innate Immune DNA Sensor for Mycobacterium tuberculosis. Cell Host Microbe 17, 820-828. doi: 10.1016/j.chom. 2015.05.005

Compston, A., and Coles, A. (2008). Multiple sclerosis. Lancet 372, 1502-1517. doi: 10.1016/S0140-6736(08)61620-7

Cook, K. W., Crooks, J., Hussain, K., O’Brien, K., Braitch, M., Kareem, H., et al. (2015). Helicobacter pylori infection reduces disease severity in an experimental model of multiple sclerosis. Front. Microbiol. 6:52. doi: $10.3389 /$ fmicb. 2015.00052

Desvignes, L. P., and Ernst, J. D. (2013). Taking sides: interferons in leprosy. Cell Host Microbe 13, 377-378. doi: 10.1016/j.chom.2013.04.001

Di Pietro, M., Filardo, S., Falasca, F., Turriziani, O., and Sessa, R. (2017). Infectious agents in atherosclerotic cardiovascular diseases through oxidative stress. Int. J. Mol. Sci. 18:2459. doi: 10.3390/ijms18112459

Ding, Y., Ren, J., Yu, H., Yu, W., and Zhou, Y. (2018). Porphyromonas gingivalis, a periodontitis causing bacterium, induces memory impairment and age-dependent neuroinflammation in mice. Immun Ageing. 15:6. doi: 10.1186/s12979-017-0110-7

Dobbs, R. J., Charlett, A., Dobbs, S. M., Weller, C. A, Ibrahim, M. A., Iguodala, O., et al. (2012). Leukocyte-subset counts in idiopathic parkinsonism provide clues to a pathogenic pathway involving small intestinal bacterial overgrowth. A surveillance study. Gut Pathog 4:12. doi: 10.1186/1757-4749-4-12 
Dobbs, S. M., Charlett, A., Dobbs, R. J., Weller, C., Iguodala, O., Smee, C., et al. (2013). Antimicrobial surveillance in idiopathic parkinsonism: indicationspecific improvement in hypokinesia following Helicobacter pylori eradication and non-specific effect of antimicrobials for other indications in worsening rigidity. Helicobacter 18, 187-196. doi: 10.1111/hel.12035

Domingues, C., da Cruz E Silva, O. A. B., and Henriques, A. G. (2017). Impact of cytokines and chemokines on Alzheimer's disease neuropathological hallmarks. Curr. Alzheimer Res. 14, 870-882. doi: 10.2174/1567205014666170317113606

Dominy, S. S., Lynch, C., Ermini, F., Benedyk, M., Marczyk, A., Konradi, A., et al. (2019). Porphyromonas gingivalis in Alzheimer's disease brains: Evidence for disease causation and treatment with small-molecule inhibitors. Sci. Adv. 5:eaau3333. doi: 10.1126/sciadv.aau3333

Dungan, L. S., McGuinness, N. C., Boon, L., Lynch, M. A., and Mills, K. H. G. (2014). Innate IFN- $\gamma$ promotes development of experimental autoimmune encephalomyelitis: a role for NK cells and M1 macrophages. Eur. J. Immunol. 44, 2903-2917. doi: 10.1002/eji.201444612

Eidson, L. N., Kannarkat, G. T., Barnum, C. J., Chang, J., Chung, J., CaspellGarcia, C., et al. (2017). Candidate inflammatory biomarkers display unique relationships with alpha-synuclein and correlate with measures of disease severity in subjects with Parkinson's disease. J. Neuroinflammation 14:164. doi: 10.1186/s12974-017-0935-1

Ejlerskov, P., Hultberg, J. G., Wang, J., Carlsson, R., Ambjørn, M., Kuss, M., et al. (2015). Lack of neuronal IFN- $\beta$-IFNAR causes lewy body- and Parkinson's disease-like dementia. Cell 163, 324-339. doi: 10.1016/j.cell.2015.08.069

Fani, L., Wolters, F. J., Ikram, M. K., Bruno, M. J., Hofman, A., Koudstaal, P. J., et al. (2018). Helicobacter pylori and the risk of dementia: a population-based study. Alzheimers Dement 14, 1377-1382. doi: 10.1016/j.jalz.2018.05.005

Fiesel, F. C., Ando, M., Hudec, R., Hill, A. R., Castanedes-Casey, M., Caulfield, T. R., et al. (2015). (Patho-)physiological relevance of PINK1-dependent ubiquitin phosphorylation. EMBO Rep. 16, 1114-1130. doi: 10.15252/embr.201540514

Franco, L. H., Nair, V. R., Scharn, C. R., Xavier, R. J., Torrealba, J. R., Shiloh, M. U., et al. (2017). The ubiquitin ligase Smurf1 functions in selective autophagy of Mycobacterium tuberculosis and anti-tuberculous host defense. Cell Host Microbe 21, 59-72. doi: 10.1016/j.chom.2016.11.002

Furlan, R., Brambilla, E., Ruffini, F., Poliani, P. L., Bergami, A., Marconi, P. C., et al. (2001). Intrathecal delivery of IFN-gamma protects C57BL/6 mice from chronic-progressive experimental autoimmune encephalomyelitis by increasing apoptosis of central nervous system-infiltrating lymphocytes. J. Immunol. 167, 1821-1829. doi: 10.4049/jimmunol.167.3.1821

Gardet, A., Benita, Y., Li, C., Sands, B. E., Ballester, I., Stevens, C., et al. (2010). LRRK2 is involved in the IFN- $\gamma$ response and host response to pathogens. J. Immunol. 185, 5577-5585. doi: 10.4049/jimmunol.1000548

Gérard, H. C., Dreses-Werringloer, U., Wildt, K. S., Deka, S., Oszust, C., Balin, B. J., et al. (2006). Chlamydophila (Chlamydia) pneumoniae in the Alzheimer's brain. FEMS Immunol. Med. Microbiol. 48, 355-366. doi: 10.1111/j.1574-695X.2006.00154.x

Giaime, E., Tong, Y., Wagner, L. K., Yuan, Y., Huang, G., and Shen, J. (2017). Age-dependent dopaminergic neurodegeneration and impairment of the autophagy-lysosomal pathway in LRRK-deficient mice. Neuron 96, 796.e6-807.e6. doi: 10.1016/j.neuron.2017.09.036

Gieffers, J., Reusche, E., Solbach, W., and Maass, M. (2000). Failure to detect Chlamydia pneumoniae in brain sections of Alzheimer's disease patients. J. Clin. Microbiol. 38, 881-882.

Gladkova, C., Maslen, S. L., Skehel, J. M., and Komander, D. (2018). Mechanism of parkin activation by PINK1. Nature 559, 410-414. doi: 10.1038/s41586-018-0224-x

Greene, J.C., Whitworth, A.J., Andrews, L.A., Parker, T.J., and Pallanck, L.J. (2005). Genetic and genomic studies of Drosophila parkin mutants implicates oxidating stress and innate immune responses in pathogenesis. Hum. Mol. Gene. 14, 799-811. doi: 10.1093/hmg/ddi074

Griffin, W. S., Liu, L., Li, Y., Mrak, R. E., and Barger, S. W. (2006). Interleukin1 mediates Alzheimer and Lewy body pathologies. J Neuroinflammation 3, 5. doi: 10.1186/1742-2094-3-5

Hafezi-Moghadam, A., Thomas, K. L., and Wagner, D. D. (2007). ApoE deficiency leads to a progressive age-dependent blood-brain barrier leakage. Am. J. Physiol. Cell Physiol. 292, C1256-C1262. doi: 10.1152/ajpcell.00563.2005

Harris, S. A., and Harris, E. A. (2015). Herpes simplex virus type 1 and other pathogens are key causative factors in sporadic
Alzheimer's disease. J. Alzheimers Dis. 48, 319-353. doi: 10.3233/ JAD-142853

Härtlova, A., Herbst, S., Peltier, J., Rodgers, A., Bilkei-Gorzo, O., Fearns, A., et al. (2018). LRRK2 is a negative regulator of Mycobacterium tuberculosis phagosome maturation in macrophages. EMBO J. 37:e98694. doi: 10.15252/embj.201798694

Hashim, H., Azmin, S., Razlan, H., Yahya, N. W., Tan, H. J., Manaf, M. R., et al. (2014). Eradication of Helicobacter pylori infection improves levodopa action, clinical symptoms and quality of life in patients with Parkinson's disease. PLoS ONE 9:e112330. doi: 10.1371/journal.pone.0112330

Heiss, C. N., and Olofsson, L. E. (2019). The role of the gut microbiota in development, function and disorders of the central nervous system and the enteric nervous system. J. Neuroendocrinol. 106, e12684. doi: 10.1111/jne.12684

Hsieh, C.-H., Shaltouki, A., Gonzalez, A. E., Bettencourt da Cruz, A., Burbulla, L. F., St Lawrence, E., et al. (2016). Functional impairment in miro degradation and mitophagy is a shared feature in familial and sporadic Parkinson's disease. Cell Stem Cell 19, 709-724. doi: 10.1016/j.stem.2016.08.002

Ieni, A., Barresi, V., Rigoli, L., Fedele, F., Tuccari, G., and Caruso, R. A. (2016). Morphological and cellular features of innate immune reaction in Helicobacter pylori gastritis: a brief review. Int. J. Mol. Sci. 17:109. doi: 10.3390/ijms17010109

Ilievski, V., Zuchowska, P. K., Green, S. J., Toth, P. T., Ragozzino, M. E., Le, K., et al. (2018). Chronic oral application of a periodontal pathogen results in brain inflammation, neurodegeneration and amyloid beta production in wild type mice. PLoS ONE 13:e0204941. doi: 10.1371/journal.pone.0204941

Iqbal, K., Liu, F., Gong, C.-X., and Grundke-Iqbal, I. (2010). Tau in Alzheimer disease and related tauopathies. Curr. Alzheimer Res. 7, 656-664. doi: 10.2174/156720510793611592

Jahn, H. U., Krüll, M., Wuppermann, F. N., Klucken, A. C., Rosseau, S., Seybold, J., et al. (2000). Infection and activation of airway epithelial cells by Chlamydia pneumoniae. J. Infect. Dis. 182, 1678-1687. doi: 10.1086/317608

Jaruvongvanich, V., Sanguankeo, A., Jaruvongvanich, S., and Upala, S. (2016). Association between Helicobacter pylori infection and multiple sclerosis: a systematic review and meta-analysis. Mult. Scler Relat. Disord. 7, 92-97. doi: 10.1016/j.msard.2016.03.013

Joosten, L. A., Radstake, T. R., Lubberts, E., van den Bersselaar, L. A., van Riel, P. L., van Lent, P. L., et al. (2003). Association of interleukin-18 expression with enhanced levels of both interleukin- $1 \beta$ and tumor necrosis factor alpha in knee synovial tissue of patients with rheumatoid arthritis. Arthritis Rheum. 48, 339-347. doi: 10.1002/art.10814

Kagan, V. E., Jiang, J., Huang, Z., Tyurina, Y. Y., Desbourdes, C., Cottet-Rousselle, C., et al. (2016). NDPK-D (NM23-H4)-mediated externalization of cardiolipin enables elimination of depolarized mitochondria by mitophagy. Cell Death Differ. 23, 1140-1151. doi: 10.1038/cdd.2015.160

Kane, L.A., Lazarou, M., Fogel, A.I., Li, Y., Yamano, K., Sarraf, S.A., et al. (2014). PINK1 phosphorylates ubiquitin to activate Parkin E3 ubiquitin ligase activity. J. Cell Biol. 205, 143-153. doi: 10.1083/jcb.201402104

Kann, O., and Kovács, R. (2007). Mitochondria and neuronal activity. Am. J. Physiol. Cell Physiol. 292, C641-C657. doi: 10.1152/ajpcell.00222.2006

Kazlauskaite, A., and Muqit, M. M. (2015). PINK1 and Parkin- mitochondrial interplay between phosphorylation and ubiquitylation in Parkinson's disease. FEBS J. 282, 215-223. doi: 10.1111/febs.13127

Kebir, H., Kreymborg, K., Ifergan, I., Dodelet-Devillers, A., Cayrol, R., Bernard, M., et al. (2007). Human TH17 lymphocytes promote blood-brain barrier disruption and central nervous system inflammation. Nat. Med. 13, 1173-1175. doi: $10.1038 / \mathrm{nm} 1651$

Kern, J. M., Maass, V., and Maass, M. (2009). Molecular pathogenesis of chronic Chlamydia pneumoniae infection: a brief overview. Clin. Microbiol. Infect. 15, 36-41. doi: 10.1111/j.1469-0691.2008.02631.x

Khaibullin, T., Ivanova, V., Martynova, E., Cherepnev, G., Khabirov, F., Granatov, E., et al. (2017). Elevated levels of proinflammatory cytokines in cerebrospinal fluid of multiple sclerosis patients. Front. Immunol. 8:531. doi: 10.3389/fimmu.2017.00531

Kim, Y., Park, J., Kim, S., Song, S., Kwon, S.-K., Lee, S.-H., et al. (2008). PINK1 controls mitochondrial localization of Parkin through direct phosphorylation. Biochem. Biophys. Res. Commun. 377, 975-980. doi: 10.1016/j.bbrc. 2008.10.104

Kim, Y. M., Im, J. Y., Han, S. H., Kang, H. S., and Choi, I. (2000). IFN-gamma upregulates IL-18 gene expression via IFN consensus sequence-binding protein 
and activator protein-1 elements in macrophages. J. Immunol. 165, 3198-3205. doi: 10.4049/jimmunol.165.6.3198

Kondapalli, C., Kazlauskaite, Ag., Zhang, N., Woodroof, H.I., Campbell, D.G., Gourlay, R., et al. (2012). PINK1 is activated by mitochondrial membrane potential depolarization and stimulates Parkin E3 ligase activity by phosphorylation Serine 65. Open Biol. 2:12008. doi: 10.1098/rsob.120080

Kountouras, J., Boziki, M., Gavalas, E., Zavos, C., Deretzi, G., Grigoriadis, N., et al. (2009). Increased cerebrospinal fluid Helicobacter pylori antibody in Alzheimer's disease. Int. J. Neurosci. 119, 765-777. doi: 10.1080/00207450902782083

Koyano, F., Okatsu, K., Kosako, H., Tamura, Y., Go, E., Kimura, M., et al. (2014). Ubiquitin is phosphorylated by PINK1 to activate parkin. Nature 510, 162-166. doi: 10.1038/nature13392

Kügler, S., Böcker, K., Heusipp, G., Greune, L., Kim, K. S., and Schmidt, M. A. (2007). Pertussis toxin transiently affects barrier integrity, organelle organization and transmigration of monocytes in a human brain microvascular endothelial cell barrier model. Cell. Microbiol. 9, 619-632. doi: 10.1111/j.1462-5822.2006.00813.x

Kustrimovic, N., Comi, C., Magistrelli, L., Rasini, E., Legnaro, M., Bombelli, R., et al. (2018). Parkinson's disease patients have a complex phenotypic and functional Th1 bias: cross-sectional studies of $\mathrm{CD}^{4+} \mathrm{Th} 1 / \mathrm{Th} 2 / \mathrm{T} 17$ and Treg in drug-naïve and drug-treated patients. J. Neuroinflammation 15:205. doi: 10.1186/s12974-018-1248-8

Lattin, J., Zidar, D. A., Schroder, K., Kellie, S., Hume, D. A., and Sweet, M. J. (2007). G-protein-coupled receptor expression, function, and signaling in macrophages. J. Leukoc. Biol. 82, 16-32. doi: 10.1189/jlb.0107051

Lee, H. J., and Chung, K. C. (2012). PINK1 positively regulates IL-1 $\beta$-mediated signaling through Tollip and IRAK1 modulation. J Neuroinflammation 9:271. doi: 10.1186/1742-2094-9-271

Lee, W. Y., Yoon, W. T., Shin, H. Y., Jeon, S. H., and Rhee, P.-L. (2008). Helicobacter pylori infection and motor fluctuations in patients with Parkinson's disease. Mov. Disord. 23, 1696-1700. doi: 10.1002/mds.22190

Li, W., Minohara, M., Su, J. J., Matsuoka, T., Osoegawa, M., Ishizu, T., et al. (2007). Helicobacter pylori infection is a potential protective factor against conventional multiple sclerosis in the Japanese population. J. Neuroimmunol. 184, 227-231. doi: 10.1016/j.jneuroim.2006.12.010

Li, Y., Liu, L., Barger, S. W., and Griffin, W. S. (2003). Interleukin-1 mediates pathological effects of microglia on tau phosphorylation and on synaptophysin synthesis in cortical neurons through a p38-MAPK pathway. J. Neurosci. 23, 1605-1611. doi: 10.1523/JNEUROSCI.23-05-01605.2003

Lim, C., Hammond, C. J., Hingley, S. T., and Balin, B. J. (2014). Chlamydia pneumoniae infection of monocytes in vitro stimulates innate and adaptive immune responses relevant to those in Alzheimer's disease. $J$ Neuroinflammation 11:217. doi: 10.1186/s12974-014-0217-0

Lin, P. L., and Flynn, J. L. (2010). Understanding latent tuberculosis: a moving target. J. Immunol. 185, 15-22. doi: 10.4049/jimmunol.0903856

Liu, W., Liu, X., Li, Y., Zhao, J., Liu, Z., Hu, Z., et al. (2017). LRRK2 promotes the activation of NLRC4 inflammasome during Salmonella Typhimurium infection. J. Exp. Med. 214, 3051-3066. doi: 10.1084/jem.20170014

Liu, Z., Lee, J., Krummey, S., Lu, W., Cai, H., and Lenardo, M. J. (2011). The kinase LRRK2 is a regulator of the transcription factor NFAT that modulates the severity of inflammatory bowel disease. Nat. Immunol. 12, 1063-1070. doi: 10.1038/ni.2113

Londoño, D., and Cadavid, D. (2010). Bacterial lipoproteins can disseminate from the periphery to inflame the brain. Am. J. Pathol. 176, 2848-2857. doi: 10.2353/ajpath.2010.091235

Loscher, C. E., Donnelly, S., Lynch, M. A., and Mills, K. H. (2000a). Induction of inflammatory cytokines in the brain following respiratory infection with Bordetella pertussis. J. Neuroimmunol. 102, 172-181. doi: 10.1016/S0165-5728(99)00177-0

Loscher, C. E., Donnelly, S., Mills, K. H., and Lynch, M. A. (2000b). Interleukin-1 $\beta$-dependent changes in the hippocampus following parenteral immunization with a whole cell pertussis vaccine. J. Neuroimmunol. 111, 68-76. doi: 10.1016/S0165-5728(00)00366-0

MacDonald, A. B., and Miranda, J. M. (1987). Concurrent neocortical borreliosis and Alzheimer's disease. Hum. Pathol. 18, 759-761. doi: 10.1016/S0046-8177(87)80252-6
MacIntyre, A., Abramov, R., Hammond, C. J., Hudson, A. P., Arking, E. J., Little, C. S., et al. (2003). Chlamydia pneumoniae infection promotes the transmigration of monocytes through human brain endothelial cells. J. Neurosci. Res. 71, 740-750. doi: 10.1002/jnr.10519

Main, B. S., Zhang, M., Brody, K. M., Ayton, S., Frugier, T., Steer, D., et al. (2016). Type-1 interferons contribute to the neuroinflammatory response and disease progression of the MPTP mouse model of Parkinson's disease. Glia 64, 1590-1604. doi: 10.1002/glia.23028

Mamais, A., Manzoni, C., Nazish, I., Arber, C., Sonustun, B., Wray, S., et al. (2018). Analysis of macroautophagy related proteins in G2019S LRRK2 Parkinson's disease brains with Lewy body pathology. Brain Res. 1701, 75-84. doi: 10.1016/j.brainres.2018.07.023

Manca, C., Tsenova, L., Bergtold, A., Freeman, S., Tovey, M., Musser, J. M., et al. (2001). Virulence of a Mycobacterium tuberculosis clinical isolate in mice is determined by failure to induce Th1 type immunity and is associated with induction of IFN- $\alpha / \beta$. Proc. Natl. Acad. Sci. U.S.A. 98, 5752-5757. doi: 10.1073/pnas.091096998

Manzanillo, P. S., Ayres, J. S., Watson, R. O., Collins, A. C., Souza, G., Rae, C. S., et al. (2013). The ubiquitin ligase parkin mediates resistance to intracellular pathogens. Nature 501, 512-516. doi: 10.1038/ nature 12566

Manzoni, C. (2012). LRRK2 and autophagy: a common pathway for disease. 40, 1147-1151. doi: 10.1042/BST20120126

Marcinek, P., Jha, A.N., Shinde, V., Sundaramoorthy, C., Rajkumar, R., Suryadevara, N.C., et al. (2013). LRRK2 and RIPK2 variants in the NOD 2-mediated signaling pathway are associated with susceptibility to Mycobacterium leprae in Indian populations. PLoS ONE 8:e73103. doi: 10.1371/journal.pone.0073103

Marques, A. R., Weir, S. C., Fahle, G. A., and Fischer, S. H. (2000). Lack of evidence of Borrelia involvement in Alzheimer's disease. J. Infect. Dis. 182, 1006-1007. doi: $10.1086 / 315792$

Matheoud, D., Sugiura, A., Bellemare-Pelletier, A., Laplante, A., Rondeau, C., Chemali, M., et al. (2016). Parkinson's disease-related proteins PINK1 and parkin repress mitochondrial antigen presentation. Cell 166, 314-327. doi: 10.1016/j.cell.2016.05.039

Mayer-Barber, K. D., Andrade, B. B., Oland, S. D., Amaral, E. P., Barber, D. L., Gonzales, J., et al. (2014). Host-directed therapy of tuberculosis based on interleukin-1 and type I interferon crosstalk. Nature 511, 99-103. doi: 10.1038/nature13489

McGee, D. J., Lu, X.-H., and Disbrow, E. A. (2018). Stomaching the possibility of a pathogenic role for Helicobacter pylori in Parkinson's disease. J. Parkinsons Dis. 8, 367-374. doi: 10.3233/JPD-181327

McManus, R. M., Higgins, S. C., Mills, K. H. G., and Lynch, M. A. (2014). Respiratory infection promotes $\mathrm{T}$ cell infiltration and amyloid- $\beta$ deposition in APP/PS1 mice. Neurobiol. Aging 35, 109-121. doi: 10.1016/j.neurobiolaging.2013.07.025

Miklossy, J. (2015). Historic evidence to support a causal relationship between spirochetal infections and Alzheimer's disease. Front. Aging Neurosci. 7:46. doi: 10.3389/fnagi.2015.00046

Miklossy, J., Khalili, K., Gern, L., Ericson, R. L., Darekar, P., Bolle, L., et al. (2004). Borrelia burgdorferi persists in the brain in chronic lyme neuroborreliosis and may be associated with Alzheimer disease. J. Alzheimers Dis. 6, 639-49discussion 673-81. doi: 10.3233/JAD-2004-6608

Miklossy, J., Kis, A., Radenovic, A., Miller, L., Forro, L., Martins, R., et al. (2006). Beta-amyloid deposition and Alzheimer's type changes induced by Borrelia spirochetes. Neurobiol. Aging 27, 228-236. doi: 10.1016/j.neurobiolaging.2005.01.018

Mira, M. T., Alcaïs, A., Nguyen, V. T., Moraes, M. O., Di Flumeri, C., Vu, H. T., et al. (2004). Susceptibility to leprosy is associated with PARK2 and PACRG. Nature 427, 636-640. doi: 10.1038/nature02326

Mudò, G., Frinchi, M., Nuzzo, D., Scaduto, P., Plescia, F., Massenti, M. F., et al. (2019). Anti-inflammatory and cognitive effects of interferon- $\beta 1 \mathrm{a}$ (IFN $\beta 1$ a) in a rat model of Alzheimer's disease. J. Neuroinflammation 16:44. doi: 10.1186/s12974-019-1417-4

Newman, L. E., and Shadel, G. S. (2018). Pink1/Parkin link inflammation, mitochondrial stress, and neurodegeneration. J. Cell Biol. 217, 3327-3329. doi: $10.1083 /$ jcb. 201808118 
Nielsen, H. H., Qiu, J., Friis, S., Wermuth, L., and Ritz, B. (2012). Treatment for Helicobacter pylori infection and risk of Parkinson's disease in Denmark. Eur. J. Neurol. 19, 864-869. doi: 10.1111/j.1468-1331. 2011.03643.x

Noble, J. M., Scarmeas, N., Celenti, R. S., Elkind, M. S., Wright, C. B., Schupf, N., et al. (2014). Serum IgG antibody levels to periodontal microbiota are associated with incident Alzheimer disease. PLoS ONE 9:e114959. doi: 10.1371/journal.pone.0114959

Oberstein, T. J., Taha, L., Spitzer, P., Hellstern, J., Herrmann, M., Kornhuber, J., et al. (2018). Imbalance of circulating Th17 and regulatory $\mathrm{T}$ cells in Alzheimer's disease: a case control study. Front. Immunol. 9:1213. doi: 10.3389/fimmu.2018.01213

Paré, A., Mailhot, B., Lévesque, S. A., Juzwik, C., Ignatius Arokia Doss, P. M., Lécuyer, M.-A., et al. (2018). IL-1 $\beta$ enables CNS access to CCR2hi monocytes and the generation of pathogenic cells through GM-CSF released by CNS endothelial cells. Proc. Natl. Acad. Sci. U.S.A. 115, E1194-E1203. doi: $10.1073 /$ pnas. 1714948115

Pickrell, A. M., Huang, C.-H., Kennedy, S. R., Ordureau, A., Sideris, D. P., Hoekstra, J. G., et al. (2015). Endogenous parkin preserves dopaminergic substantia nigral neurons following mitochondrial DNA mutagenic stress. Neuron 87, 371-381. doi: 10.1016/j.neuron.2015.06.034

Pierantozzi, M., Pietroiusti, A., Brusa, L., Galati, S., Stefani, A., Lunardi, G., et al. (2006). Helicobacter pylori eradication and l-dopa absorption in patients with PD and motor fluctuations. Neurology 66, 1824-1829. doi: 10.1212/01.wnl.0000221672.01272.ba

Pierantozzi, M., Pietroiusti, A., Sancesario, G., Lunardi, G., Fedele, E., Giacomini, P., et al. (2001). Reduced L-dopa absorption and increased clinical fluctuations in Helicobacter pylori-infected Parkinson's disease patients. Neurol. Sci. 22, 89-91. doi: 10.1007/s100720170061

Pierson, E. R., and Goverman, J. M. (2017). GM-CSF is not essential for experimental autoimmune encephalomyelitis but promotes brain-targeted disease. JCI Insight 2:e92362. doi: 10.1172/jci.insight.92362

Pisa, D., Alonso, R., Rábano, A., Rodal, I., and Carrasco, L. (2015). Different brain regions are infected with fungi in Alzheimer's disease. Sci. Rep. 5:15015. doi: $10.1038 /$ srep 15015

Poole, S., Singhrao, S. K., Chukkapalli, S., Rivera, M., Velsko, I., Kesavalu, L., et al. (2015). Active invasion of Porphyromonas gingivalis and infection-induced complement activation in ApoE ${ }^{-/-}$mice brains. J. Alzheimers Dis. 43, 67-80. doi: 10.3233/JAD-140315

Poole, S., Singhrao, S. K., Kesavalu, L., Curtis, M. A., and Crean, S. (2013). Determining the presence of periodontopathic virulence factors in short-term postmortem Alzheimer's disease brain tissue. J. Alzheimers Dis. 36, 665-677. doi: 10.3233/JAD-121918

Price, D. A., Bassendine, M. F., Norris, S. M., Golding, C., Toms, G. L., Schmid, M. L., et al. (2006). Apolipoprotein epsilon3 allele is associated with persistent hepatitis C virus infection. Gut 55, 715-718. doi: 10.1136/gut.2005.079905

Rajalingam, K., Al-Younes, H., Müller, A., Meyer, T. F., Szczepek, A. J., and Rudel, T. (2001). Epithelial cells infected with Chlamydophila pneumoniae (Chlamydia pneumoniae) are resistant to apoptosis. Infect. Immun. 69, 7880-7888. doi: 10.1128/IAI.69.12.7880-7888.2001

Rasouli, J., Ciric, B., Imitola, J., Gonnella, P., Hwang, D., Mahajan, K., et al. (2015). Expression of GM-CSF in T cells is increased in multiple sclerosis and suppressed by IFN- $\beta$ therapy. J. Immunol. 194, 5085-5093. doi: 10.4049/jimmunol.1403243

Ring, R. H., and Lyons, J. M. (2000). Failure to detect Chlamydia pneumoniae in the late-onset Alzheimer's brain. J. Clin. Microbiol. 38, 2591-2594.

Robinson, K., Argent, R. H., and Atherton, J. C. (2007). The inflammatory and immune response to Helicobacter pylori infection. Best Pract. Res. Clin. Gastroenterol. 21, 237-259. doi: 10.1016/j.bpg.2007.01.001

Rokad, F., Moseley, R., Hardy, R.S., Chukkapalli, S., Crean, S., Kesavalu, L., et al. (2017). Cerebral oxidative stress and microvasculature defects in TNF- $\alpha$ expressing transgenic and Porphyromonas gingivalis-infected $\mathrm{ApoE}^{-/-}$mice. J. Alzheimers Dis. 60:359-369. doi: 10.3233/JAD-170304

Roulis, E., Bachmann, N. L., Myers, G. S., Huston, W., Summersgill, J., Hudson, A., et al. (2015). Comparative genomic analysis of human Chlamydia pneumoniae isolates from respiratory, brain and cardiac tissues. Genomics 106, 373-383. doi: 10.1016/j.ygeno.2015.09.008
Salat, D., and Tolosa, E. (2013). Levodopa in the treatment of Parkinson's disease: current status and new developments. J. Parkinsons Dis. 3, 255-269. doi: $10.3233 / J P D-130186$

Sanchez-Guajardo, V., Barnum, C. J., Tansey, M. G., and Romero-Ramos, M. (2013). Neuroimmunological processes in Parkinson's disease and their relation to $\alpha$-synuclein: microglia as the referee between neuronal processes and peripheral immunity. ASN Neuro 5, 113-139. doi: 10.1042/AN20120066

Schildt, A., Walker, M. D., Dinelle, K., Miao, Q., Schulzer, M., O’Kusky, J., et al. (2019). Single inflammatory trigger leads to neuroinflammation in LRRK2 rodent model without degeneration of dopaminergic neurons. J. Parkinsons Dis. 9, 121-139. doi: 10.3233/JPD-181446

Schröder, J. B., Pawlowski, M., Meyer Zu Hörste, G., Gross, C. C., Wiendl, H., Meuth, S. G., et al. (2018). Immune cell activation in the cerebrospinal fluid of patients with Parkinson's disease. Front. Neurol. 9:1081. doi: 10.3389/fneur.2018.01081

Scott, K. M., Kouli, A., Yeoh, S. L., Clatworthy, M. R., and WilliamsGray, C. H. (2018). A systematic review and meta-analysis of alpha synuclein auto-antibodies in Parkinson's disease. Front. Neurol. 9:815. doi: 10.3389/fneur.2018.00815

Semper, R. P., Mejías-Luque, R., Groß, C., Anderl, F., Müller, A., Vieth, M., et al. (2014). Helicobacter pylori-induced IL-1 $\beta$ secretion in innate immune cells is regulated by the NLRP3 inflammasome and requires the cag pathogenicity island. J. Immunol. 193, 3566-3576. doi: 10.4049/jimmunol.1400362

Serrano-Coll, H., Salazar-Peláez, L., Acevedo-Saenz, L., and Cardona-Castro, N. (2018). Mycobacterium leprae-induced nerve damage: direct and indirect mechanisms. Pathog Dis. 76, 429. doi: 10.1093/femspd/fty062

Shao, L., Liu, X., Zhu, S., Liu, C., Gao, Y., and Xu, X. (2018). The role of smurf1 in neuronal necroptosis after lipopolysaccharide-induced neuroinflammation. Cell. Mol. Neurobiol. 38, 809-816. doi: 10.1007/s10571-017-0553-6

Shen, C.-H., Chou, C.-H., Liu, F.-C., Lin, T.-Y., Huang, W.-Y., Wang, Y.C., et al. (2016). Association between tuberculosis and Parkinson disease: a nationwide, population-based cohort study. Medicine (Baltimore) 95:e2883. doi: 10.1097/MD.0000000000002883

Singhrao, S. K., Chukkapalli, S., Poole, S., Velsko, I., Crean, S. J., and Kesavalu, L. (2017). Chronic Porphyromonas gingivalis infection accelerates the occurrence of age-related granules in $\mathrm{ApoE}^{-/-}$mice brains. J. Oral. Microbiol. 9:1270602. doi: 10.1080/20002297.2016.1270602

Sliter, D. A., Martinez, J., Hao, L., Chen, X., Sun, N., Fischer, T. D., et al. (2018). Parkin and PINK1 mitigate STING-induced inflammation. Nature 561, 258-262. doi: 10.1038/s41586-018-0448-9

Smith, W. W., Pei, Z., Jiang, H., Moore, D. J., Liang, Y., West, A. B., et al. (2005). Leucine-rich repeat kinase 2 (LRRK2) interacts with parkin, and mutant LRRK2 induces neuronal degeneration. Proc. Natl. Acad. Sci. U.S.A. 102, 18676-18681. doi: 10.1073/pnas.0508052102

Sommer, A., Maxreiter, F., Krach, F., Fadler, T., Grosch, J., Maroni, M., et al. (2018). Th17 lymphocytes induce neuronal cell death in a human iPSC-based model of Parkinson's disease. Cell Stem. Cell 23, 123.e6-131.e6. doi: 10.1016/j.stem.2018.06.015

Sriram, S., Ljunggren-Rose, A., Yao, S.-Y., and Whetsell, W. O. (2005). Detection of chlamydial bodies and antigens in the central nervous system of patients with multiple sclerosis. J. Infect. Dis. 192, 1219-1228. doi: 10.1086/431518

Sriram, S., Stratton, C. W., Yao, S., Tharp, A., Ding, L., Bannan, J. D., et al. (1999). Chlamydia pneumoniae infection of the central nervous system in multiple sclerosis. Ann. Neurol. 46, 6-14. doi: 10.1002/1531-8249(199907)46:1<6::AID-ANA4>3.0.CO;2-M

Stanley, S. A., Johndrow, J. E., Manzanillo, P., and Cox, J. S. (2007). The Type I IFN response to infection with Mycobacterium tuberculosis requires ESX-1-mediated secretion and contributes to pathogenesis. J. Immunol. 178, 3143-3152. doi: 10.4049/jimmunol.178.5.3143

Storelli, E., Cassina, N., Rasini, E., Marino, F., and Cosentino, M. (2019). Do Th17 lymphocytes and IL-17 contribute to Parkinson's disease? A systematic review of available evidence. Front. Neurol. 10:13. doi: 10.3389/fneur.2019.00013

Su, X., and Chen, H.-L. (2014). Chlamydia pneumoniae infection and cerebral infarction risk: a meta-analysis. Int. J. Stroke 9, 356-364. doi: 10.1111/ijs.12248

Sulzer, D., Alcalay, R. N., Garretti, F., Cote, L., Kanter, E., Agin-Liebes, J., et al. (2017). T cells from patients with Parkinson's disease recognize $\alpha$-synuclein peptides. Nature 546, 656-661. doi: 10.1038/nature22815 
Szargel, R., Shani, V., Abd Elghani, F., Mekies, L. N., Liani, E., Rott, R., et al. (2016). The PINK1, synphilin-1 and SIAH-1 complex constitutes a novel mitophagy pathway. Hum. Mol. Genet. 25, 3476-3490. doi: 10.1093/hmg/ddw189

Tachida, Y., Nakagawa, K., Saito, T., Saido, T. C., Honda, T., Saito, Y., et al. (2008). Interleukin-1 beta up-regulates TACE to enhance alpha-cleavage of APP in neurons: resulting decrease in Abeta production. J. Neurochem. 104, 1387-1393. doi: 10.1111/j.1471-4159.2007.05127.x

Tahara, K., Kim, H.-D., Jin, J.-J., Maxwell, J. A., Li, L., and Fukuchi, K. (2006). Role of toll-like receptor signalling in Abeta uptake and clearance. Brain 129, 3006-3019. doi: 10.1093/brain/awl249

Tan, A. H., Mahadeva, S., Marras, C., Thalha, A. M., Kiew, C. K., Yeat, C. M., et al. (2015). Helicobacter pylori infection is associated with worse severity of Parkinson's disease. Parkinsonism Relat. Disord. 21, 221-225. doi: 10.1016/j.parkreldis.2014.12.009

Teles, R. M. B., Graeber, T. G., Krutzik, S. R., Montoya, D., Schenk, M., Lee, D. J., et al. (2013). Type I interferon suppresses type II interferontriggered human anti-mycobacterial responses. Science 339, 1448-1453. doi: $10.1126 /$ science. 1233665

Tilly, K., Rosa, P. A., and Stewart, P. E. (2008). Biology of infection with Borrelia burgdorferi. Infect. Dis. Clin. North Am. 22, 217-34-v. doi: 10.1016/j.idc.2007.12.013

Tuddenham, S., and Ghanem, K. G. (2018). Neurosyphilis: knowledge gaps and controversies. Sex Transm Dis. 45, 147-151. doi: 10.1097/OLQ.0000000000000723

Verreault, R., Laurin, D., Lindsay, J., and De Serres, G. (2001). Past exposure to vaccines and subsequent risk of Alzheimer's disease. CMAJ 165, 1495-1498.

Villa, E., Marchetti, S., and Ricci, J.-E. (2018). No parkin zone: mitophagy without Parkin. Trends Cell Biol. 28, 882-895. doi: 10.1016/j.tcb.2018.07.004

Wang, D., Xu, L., Lv, L., Su, L.Y., Fan, Y., Zhang, D.F., et al. (2015). Association of the LRRK2 genetic polymorphisms with leprosy in Han Chinese from Southwest China. Genes Immun. 16, 112-119. doi: 10.1038/gene.2014.72

Wang, D., Zhang, D.-F., Feng, J.-Q., Li, G.-D., Li, X.-A., Yu, X.-F., et al. (2016). Common variants in the PARL and PINK1 genes increase the risk to leprosy in Han Chinese from South China. Sci. Rep. 6:37086. doi: 10.1038/ srep37086

Wang, X., Yan, M. H., Fujioka, H., Liu, J., Wilson-Delfosse, A., Chen, S. G., et al. (2012). LRRK2 regulates mitochondrial dynamics and function through direct interaction with DLP1. Hum. Mol. Genet. 21, 1931-1944. doi: $10.1093 / \mathrm{hmg} / \mathrm{dds} 003$

Ward, J. I., Cherry, J. D., Chang, S.-J., Partridge, S., Lee, H., Treanor, J., et al. (2005). Efficacy of an acellular pertussis vaccine among adolescents and adults. N. Engl. J. Med. 353, 1555-1563. doi: 10.1056/NEJMoa050824

Warfel, J. M., Zimmerman, L. I., and Merkel, T. J. (2014). Acellular pertussis vaccines protect against disease but fail to prevent infection and transmission in a nonhuman primate model. Proc. Natl. Acad. Sci. U.S.A. 111, 787-792. doi: 10.1073/pnas.1314688110

Wassermann, R., Gulen, M. F., Sala, C., Perin, S. G., Lou, Y., Rybniker, J., et al. (2015). Mycobacterium tuberculosis differentially activates cGAS- and inflammasome-dependent intracellular immune responses through ESX-1. Cell Host Microbe 17, 799-810. doi: 10.1016/j.chom.2015.05.003

Watson, R. O., Bell, S. L., MacDuff, D. A., Kimmey, J. M., Diner, E. J., Olivas, J., et al. (2015). The cytosolic sensor cGAS detects Mycobacterium tuberculosis DNA to induce Type I interferons and activate autophagy. Cell Host Microbe 17, 811-819. doi: 10.1016/j.chom.2015.05.004

Watson, R. O., Manzanillo, P. S., and Cox, J. S. (2012). Extracellular M. tuberculosis DNA targets bacteria for autophagy by activating the host DNA-sensing pathway. Cell 150, 803-815. doi: 10.1016/j.cell.2012.06.040
West, A.P., Khoury-Hanold, W., Staron, M., Tal, M.C., Pineda, C.M., Lang, S.M., et al. (2015) Mitochondrial DNA stress primers the antiviral innate immune response. 520, 553-557. doi: 10.1038/nature14156

West, A. P., and Shadel, G. S. (2017). Mitochondrial DNA in innate immune responses and inflammatory pathology. Nat. Rev. Immunol. 17, 363-375. doi: 10.1038/nri.2017.21

Wilske, B., Fingerle, V., and Schulte-Spechtel, U. (2007). Microbiological and serological diagnosis of Lyme borreliosis. FEMS Immunol. Med. Microbiol. 49, 13-21. doi: 10.1111/j.1574-695X.2006.00139.x

Wooten, R. M., Ma, Y., Yoder, R. A., Brown, J. P., Weis, J. H., Zachary, J. F., et al. (2002). Toll-like receptor 2 is required for innate, but not acquired, host defense to Borrelia burgdorferi. J. Immunol. 168, 348-355. doi: 10.4049/jimmunol.168.1.348

Yao, G., Wang, P., Luo, X.-D., Yu, T.-M., Harris, R. A., and Zhang, X.-M. (2016). Meta-analysis of association between Helicobacter pylori infection and multiple sclerosis. Neurosci. Lett. 620, 1-7. doi: 10.1016/j.neulet.2016.03.037

Yeung, K. H. T., Duclos, P., Nelson, E. A. S., and Hutubessy, R. C. W. (2017). An update of the global burden of pertussis in children younger than 5 years: a modelling study. Lancet Infect. Dis. 17, 974-980. doi: 10.1016/S1473-3099(17)30390-0

Yirmiya, R., and Goshen, I. (2011). Immune modulation of learning, memory, neural plasticity and neurogenesis. Brain Behav. Immun. 25, 181-213. doi: 10.1016/j.bbi.2010.10.015

Yong, J., Lacan, G., Dang, H., Hsieh, T., Middleton, B., Wasserfall, C., et al. (2011). BCG vaccine-induced neuroprotection in a mouse model of Parkinson's disease. PLoS ONE 6:e16610. doi: 10.1371/journal.pone.0016610

Zhang, F.R., Huang, W., Chen, S.M., Sun, L.D., Liu, H., Li, Y., et al. (2009). Genomewide association study of leprosy. N. Engl. J. Med. 361, 2609-2618. doi: 10.1056/NEJMoa0903753

Zhang, G., deWeerd, N. A., Stifter, S. A., Liu, L., Zhou, B., Wang, W., et al. (2018). A proline deletion in IFNAR1 impairs IFN-signaling and underlies increased resistance to tuberculosis in humans. Nat. Commun. 9, 85. doi: 10.1038/s41467-017-02611-Z

Zhang, Q., Yin, Z., Li, Y., Luo, H., Shao, Z., Gao, Y., et al. (2014). Prevalence of asymptomatic Bordetella pertussis and Bordetella parapertussis infections among school children in China as determined by pooled real-time PCR: a cross-sectional study. Scand. J. Infect. Dis. 46, 280-287. doi: 10.3109/00365548. 2013.878034

Zhu, J.-H., Guo, F., Shelburne, J., Watkins, S., and Chu, C. T. (2003). Localization of phosphorylated ERK/MAP kinases to mitochondria and autophagosomes in Lewy body diseases. Brain Pathol. 13, 473-481. doi: 10.1111/j.1750-3639.2003.tb00478.x

Zhu, X., Han, Y., Du, J., Liu, R., Jin, K., and Yi, W. (2017). Microbiotagut-brain axis and the central nervous system. Oncotarget 8, 53829-53838. doi: 10.18632/oncotarget.17754

Conflict of Interest Statement: The authors declare that the research was conducted in the absence of any commercial or financial relationships that could be construed as a potential conflict of interest.

Copyright (C) 2019 Patrick, Bell, Weindel and Watson. This is an open-access article distributed under the terms of the Creative Commons Attribution License (CC BY). The use, distribution or reproduction in other forums is permitted, provided the original author(s) and the copyright owner(s) are credited and that the original publication in this journal is cited, in accordance with accepted academic practice. No use, distribution or reproduction is permitted which does not comply with these terms. 